\title{
Los procesos de identificación en el trabajo del actor
}

\author{
Natalia Torres Vilar \\ Universidad de Lima \\ Lima-Perú
}

El trabajo aborda los procesos de identificación entre el actor y sus personajes. Partiendo de una revisión cronológica del concepto de identificación en la literatura psicoanalítica, y procurando diferenciarlo de algunos conceptos afines, avanzamos hacia la revisión de los escasos trabajos existentes sobre la identificación aplicada directamente al fenómeno de la actuación. En tanto el objetivo de este trabajo es observar cómo se dan efectivamente estos procesos identificatorios en la práctica del actor al crear sus personajes, se realizan cinco entrevistas en profundidad a reconocidos actores para conocer sus opiniones $y$ experiencias al respecto. Los resultados se basan en las experiencias compartidas por los entrevistados.

Identificación, actor-personajes, psicoanálisis, actuación

\section{Identification processes in the work of the actor}

The paper addresses the processes of identification between the actor and the characters he creates. Starting from a chronological review of the concept of identification in the psychoanalytic literature, and intending to differentiate the concept from others than are related, we move towards a review of the scarce existing works on identification applied directly to the acting phenomenon. Since the objective of this research is to observe how the processes of identification effectively take place in the practice of the actor while creating his characters, we interview five respected actors to know their opinions and experience on the subject. The results are based on the experiences shared by the participants.

identification, actor-characters, psychoanalysis, stage acting

Correo electrónico: ntorres@correo.ulima.edu.pe 
El trabajo de un actor supone la identificación de este con sus personajes. El actor, al explorar los límites de su personaje, también se identifica con él, juega a ser esa otra persona, ensayándose en facetas diferentes, regresiona a una etapa esencial de identificaciones. Aunque no sea su finalidad, la actuación le ofrece al actor la posibilidad de revivir y elaborar fantasías pasadas y presentes, pero con el riesgo, a veces, de quedarse atrapado en dichas identificaciones, confundiéndose en cuanto a su propia identidad, como puede observarse en el hecho de que algunos actores continúen representando sus personajes fuera del contexto teatral.

El actor se presta para la identificación con el autor, de la misma forma que con el público. Aún más, el actor, indiferenciado a veces de su personaje, se identificará con otros personajes. El fenómeno teatral, que surge del autor y culmina en un público, público de alguna manera presente también en tanto inconsciente social en la génesis de la obra, pasa necesariamente por la creación interpretativa, donde el actor es el instrumento que viabiliza los afectos implicados en el juego de inconscientes entre el autor y el público (Kaufmann, 1996). Lo que nos cuestionamos es si en la actuación, la entrega del actor a interactuar con su personaje, del mismo modo que puede ser una forma de crecimiento y consolidación personal, podría ser peligrosa si su sentido de autoidentidad no es consistente.
Se ha escrito mucho sobre los procesos creativos, pero, a pesar de ello, la literatura sobre el actor y sus identificaciones es escasa. En el presente trabajo presentamos algunos de los resultados obtenidos a partir de entrevistas en profundidad a un grupo de actores de nuestro medio, intentando describir la manera en que se dan los procesos de identificación en el trabajo del actor al crear y representar a sus personajes, así como algunos mecanismos y fenómenos intervinientes. Resaltamos, asimismo, los riesgos implicados, para el bienestar psicológico de los actores, en los procesos de identificación entre el actor y sus personajes, determinando los factores que incrementan dichos riesgos, así como los momentos específicos del proceso en los que estos riesgos se incrementan.

Los cinco actores entrevistados son ampliamente reconocidos en el medio, cuya actividad profesional es exclusiva o se dedican centralmente a la actuación, con un mínimo de 10 años de experiencia en los escenarios. Para efectos de una presentación que resguarde el anonimato de los participantes, sus nombres han sido sustituidos por nombres ficticios, y algunos datos han sido modificados, procurando, sin embargo, que se mantengan las ideas esenciales. Los nombres de los actores o directores referidos por los entrevistados en sus comentarios también han sido cambiados por otros ficticios, al igual que los nombres de los personajes 
a los que hacen referencia. Si bien entendemos que en el proceso teatral el juego de identificaciones se establece desde el autor hasta el público, pasando por los actores y el director, en el presente trabajo, por motivos de extensión, nos centraremos en el juego de identificaciones entre el actor y su personaje.

\section{DELIMITACión DEL CONCEPTO DE IDENTIFICACIÓN}

El término identificación fue utilizado por Freud ya en 1896 en su correspondencia con Fliess (Roudinesco y Plon, 1998) en donde la identificación tiene que ver con un deseo reprimido de "ser como" o de "hacer como". Pero la identificación como concepto apareció en la obra de Freud a partir de 1900, como un mecanismo histérico en La interpretación de los sueños (Freud, 1983a). Freud hizo de la identificación un concepto central en su obra (Valls, 1995), convirtiéndolo en el mecanismo en virtud del cual se constituye el sujeto. Si bien en principio la utilizó para explicar los procesos oníricos y la formación de síntomas histéricos (Freud, 1983a), en donde además observa que pueden coexistir varias identificaciones como manifestación de pluralidad psíquica, posteriormente muestra su función en la melancolía (Freud, 1983d), en los procesos narcisistas (Freud, 1983c), como forma originaria del lazo afectivo con el objeto (Freud, 1983d), y en los pro- cesos grupales, en los cuales existe una identificación recíproca entre sujetos (Freud, 1983e; 1983h).

El concepto de identificación fue trabajado paralelamente por Ferenczi (1982a, 1982b), quien se ocupó principalmente de la introyección. Se trata de un término usado inicialmente por este autor para diferenciar los procesos neuróticos de los psicóticos, en donde los primeros obedecerían a una introyección excesiva y los segundos a una proyección excesiva. Ferenczi (1982b) relacionó también los impulsos orales a la introyección y los impulsos anales a la proyección.

Lacan (Roudinesco y Plon, 1998) también hará de la identificación un concepto central en su teoría. Para él la identificación se sitúa en el registro de lo imaginario durante el estadío del espejo, y puntúa tres tiempos del complejo de Edipo. En primer lugar, una identificación con lo que se piensa que es el deseo de la madre, más tarde el descubrimiento de la ley del padre, y finalmente la simbolización de esta ley, que tiene por efecto que se asigne su verdadero lugar al deseo de la madre, permitiendo las identificaciones ulteriores constitutivas del sujeto.

Un paso importante en la modificación del mecanismo de identificación fue a partir de Melanie Klein, quien retomó el concepto de incorporación. Para ella, este concepto denota una fantasía de absorción corporal de un objeto cuya presencia física se siente después 
en el interior del cuerpo, donde ocupa un espacio y es activo (Hinshelwood, 1989). Es la forma más primitiva de internalización, vinculada con fantasías orales que reflejan el funcionamiento del proceso primario y significaría de hecho una regresión a la identificación primaria.

La introyección como mecanismo de defensa, por su lado, es planteado por Klein en 1946 como la internalización de objetos buenos externos para contrarrestar el peligro que los objetos internos, percibidos como malos, ostentan para el yo. Así, la introyección puede verse también como parte del desarrollo, en donde se va construyendo una identidad más segura y preservada de maldad. Mientras que para Klein es una defensa contra la angustia ante el mundo interno percibido como aterrador, para Freud es una defensa frente a la pérdida de un objeto externo. Para Klein (1946), la buena internalización del pecho actúa como un punto céntrico en el yo. El objeto bueno internalizado es una precondición para un yo integrado y estable.

Klein distingue (Del Valle, 1986), además, la identificación introyectiva (identificarse con algún objeto interno, llegando a ser como él) de la identificación proyectiva, en donde cierta parte del yo se segrega y se proyecta a un objeto externo. La identificación introyectiva sería parte del desarrollo normal que genera la experiencia de la identidad.
El término identificación proyectiva fue empleado originalmente por Klein (Hughes, 1990; Klein, 1946, 1955) aunque elaborado posteriormente por Rosenfeld. Según Grinberg (1978), para Rosenfeld la identificación proyectiva implica que primero se separe una representación del self y luego se desplace esta a una representación de objeto. Pero para que esto sea más que una proyección, necesitamos percatarnos inconscientemente de que aquello que hemos proyectado es nuestro, para sentir con alivio y placer que nos hemos deshecho de una parte no deseada de nuestro self. Este proceso nos permite sentir por un instante que lo que se proyecta nos pertenece, y casi inmediatamente tranquilizarnos porque ya no es nuestro sino de otro.

Grinberg (1978) nos recuerda que algunos autores insisten en que el término identificación debe reservarse para el proceso, en tanto el producto vendría a ser una introyección. Este mismo autor nos ayuda a diferenciar otros conceptos afines. Para él la identificación sería un fenómeno global que abarcaría internalizaciones y externalizaciones. A su vez, la internalización puede ser considerada como un proceso abarcativo, que incluye otros procesos y mecanismos mediante los cuales se constituye el mundo psíquico interno: incorporación, introyección e identificación. Agrega, además, en cuanto a la identificación proyectiva, que en condiciones normales, este me- 
canismo determinaría la relación de empatía con el objeto no porque permite ponerse en el lugar del otro para comprenderlo mejor, sino también por lo que evoca en él, ya que produce siempre alguna resonancia emocional en el objeto. La calidad normal del funcionamiento de la identificación proyectiva dependerá en gran medida de la calidad con que funcionaron las identificaciones proyectivas de las primeras relaciones objetales.

Otro paso importante en la comprensión de los fenómenos que nos ocupan se dio con Winnicott (Abadi, 1996, 1997; Panceira, 1997; Winnicott, 1971, 1979, 1992, 1993), quien hace de la identificación un instrumento primordial en el desarrollo del bebé. Nos dice que la madre y el bebé en principio son uno y entre ellos existe un vínculo que él llamó de "identificación primaria o identidad", a través del cual la madre centra su existencia en su hijo recién nacido para poder captar en forma directa todo lo que sucede dentro de él y satisfacer sus necesidades, las cuales él aún no puede expresar verbalmente. La identificación vendría a ser en su obra un fenómeno por el cual nos transportamos al interior de un objeto para coincidir con lo que tiene de único, y por consiguiente de inexpresable, implicando la coincidencia con el objeto mismo. Esta identificación, no solo normal en el desarrollo del infante, sino también esencial para su supervivencia, solo puede ser vivida así poste- riormente en profundas regresiones psicóticas dependientes, y es básicamente incomunicable.

Como recuerda Panceira (1997), Winnicott reconoce que el proceso de las identificaciones puede tener muchas vicisitudes. A veces, el exceso de gratificación no permite un adecuado establecimiento de la realidad, o la excesiva frustración hace que se mantenga una cierta tendencia a autogratificarse en la fantasía. El bebé necesita la atención y el amor de los padres, $y$ a veces se siente forzado a ir identificándose con lo que uno debería ser, como medio de ser aceptado, más allá de lo que auténticamente le gustaría ser. Se instala así un sí mismo engañoso, que se vinculará con otros a partir de imágenes falsas, y con poca conciencia de sus verdaderas motivaciones. Los procesos identificatorios fracasarían en la personalidad "como si" y serían reemplazados por patrones de conducta imitativa o mimética que tienen lugar sin una internalización profunda y que hacen actuar según un modelo primario de actividad especular. Nos atrevemos a agregar que actores que pudieran tener esta característica estructural estarán en mayor riesgo de que, al ensayarse en diferentes roles, se dé un enganche con una motivación de necesidad para un sí mismo difuso, que busca solidificarse en base a máscaras. Estas personas tenderán a hacer identificaciones proyectivas patológicas. El precario sentido de identidad hace que resulte difícil diferenciar entre fantasía y reali- 
dad, así como tener claridad respecto de las motivaciones propias y las de los otros.

Laplanche y Pontalis (1983), por su parte, definieron la identificación como el "proceso psicológico mediante el cual un sujeto asimila a su aspecto, una propiedad, un atributo de otro y se transforma total o parcialmente, sobre el modelo de este". La personalidad, nos dicen estos autores, se constituye y se diferencia mediante una serie de identificaciones.

En 1987, Kernberg plantea que lo que caracterizaría la identificación proyectiva, a diferencia de la proyección pura, es que en la primera se observa la tendencia a seguir experimentando el impulso a pesar de haber sido proyectado en otro. Con ello se teme a ese otro a quien se ve caracterizado por el impulso proyectado, y surge la necesidad de controlar a esa persona, lo cual se hace con frecuencia de tal modo que se suscita en ella conductas que validarían la proyección (Kernberg, 1987). Así, mientras la proyección estaría basada en una estructura centrada en la represión como defensa, la identificación proyectiva se basa en una estructura yoica centrada en la escisión y la disociación primitiva.

Kernberg (1994) nos habla también de la internalización, la cual designa para él la creación de estructuras intrapsíquicas que resultan de las interacciones reales y fantaseadas con los objetos significativos bajo el impacto de los derivados pulsionales, representados por estados afectivos específicos. La introyección, la identificación y la formación de la identidad son niveles progresivos del desarrollo de la internalización.

Las identificaciones, nos recuerda Kernberg (1994), son normalmente parciales o selectivas, implican la modificación del concepto de sí-mismo bajo la influencia del objeto. Al mismo tiempo, en la discriminación entre los aspectos del objeto que son y que no son incorporados hay un incremento de la diferenciación entre el sí-mismo y el objeto. De modo que las identificaciones tienen funciones progresivas o de promoción del crecimiento.

Las experiencias intensas alientan tanto la fusión como la diferenciación. Si el estado es de placer, el infante querrá fusionarse con quien se lo proporciona; si es de dolor, querrá separarse. Los estados de placer extremo establecen una representación indiferenciada totalmente buena del sí-mismo/objeto, dentro de la cual gradualmente se irán diferenciando después estos componentes. Los estados de extremo displacer motivan esfuerzos de huida y eliminación de ese displacer, ubicando su fuente afuera, creando en el proceso una representación fusionada totalmente mala del objeto/sí-mismo. También en ese caso el objeto y el sí-mismo se van diferenciando gradualmente.

Para Kernberg (1994) el sí-mismo siempre incluye dos capas: se le puede 
visualizar como una esfera central de representaciones del sí-mismo, y otra esfera que envuelve a la anterior, de autorreflexividad derivada de la identificación con la madre observadora y preocupada por su niño en la relación diádica original. Esto se puede entender también como un doble agrupamiento de las funciones de las representaciones del sí-mismo; un grupo se encarga de la diferenciación del sí-mismo y el otro de retener las funciones de observación de las imágenes parentales internalizadas en el sí-mismo. Esta capacidad de autopercatación es lo que falta en la psicosis. La integración longitudinal (a lo largo del tiempo) y transversal de todas las representaciones del sí-mismo en un autoconcepto central, abarcativo, es acompañada por la integración paralela de una esfera envolvente de autorreflexividad que proporciona un fondo de autoevaluación en curso. En otras palabras, la autoevaluación puede convertirse en una estructura preciosa del yo, que desempeña una función yoica superior, la de la autoobservación.

Roudinesco y Plon (1998) plantean que la identificación, concepto central en psicoanálisis, es un proceso mediante el cual el sujeto se constituye y se transforma, asimilando o apropiándose, en momentos clave de su evolución, de aspectos, atributos o rasgos de los seres humanos de su entorno. En el desarrollo normal, la identificación surge de forma gradual al ir el bebé delimi- tando la realidad así como los límites de su sí-mismo. Para ello, necesitará que otros, desde afuera, se presten para la exploración y el juego.

Para Sandler y Sandler (1999), somos incapaces de percibir un movimiento o una expresión de otro sin duplicarlo inconscientemente en nosotros mismos, mecanismo que se inhibe con el paso del tiempo. En el adulto, este sería un hecho residual que apuntaría a la empatía y la sugestión. Esto nos lleva al concepto de imitación. El niño, en sus manifestaciones más tempranas de imitación, solo puede copiar aquello que ya ha realizado por sí mismo, ejemplo de lo cual es la imitación vocal. Para imitar, había planteado ya Piaget (1969), el niño ya debe haber formado, mediante su propia acción, un esquema sensoriomotor en el que el estímulo que ha de ser copiado puede insertarse. Poco a poco, la imagen adquiere vida propia y el niño que imita a menudo no tiene la conciencia de hacerlo; su respuesta al modelo le parece originada en el interior.

Las identificaciones se pueden dar, pues, sin que haya conciencia de imitar el modelo. Incluso cuando las imitaciones del niño muestran flexibilidad y creatividad, están formadas por la variación experimental a partir de un repertorio de actos que ya ha aprendido a ejecutar. Así, la conducta de imitar solo es posible en un organismo que ya ha adquirido una matriz suficiente de acciones. En otras palabras, la imitación 
constituye un proceso activo por el cual se modifica la propia conducta establecida para hacerla más parecida a la de un modelo. No se puede imitar algo de lo cual no hay un registro previo. Esto nos parece interesante, pues, aplicado a la actuación, estaría implicando la imposibilidad del actor de interpretar personajes que de algún modo, aunque sea parcialmente, no estén inscritos en él.

La distinción entre imitación e identificación, según Sandler y Sandler (1999), está dada en que, en la primera, se intenta hacer algo que otro ha hecho, y en la segunda, se pretende ser como otro. La imitación estaría en la base de cualquier aprendizaje del tipo how to, en tanto se puede aprender de cualquier persona cómo hacer algo. El modelo sería irrelevante, sustituible, carente de importancia personal. En la identificación, el modelo sí posee importancia personal en tanto uno desea ser como el modelo, o, en todo caso, hacer las cosas como él. La identificación no es una categoría de conducta, es un mecanismo inconsciente que produce modificaciones perdurables en el sujeto. Sin embargo, ambos procesos pueden llegar a integrarse en tanto la imitación favorecería la identificación, como un precursor de esta.

La identificación es, pues, un mecanismo de aprendizaje de gran importancia para la organización de la personalidad. Interviene como proceso fundamental en la formación del yo, del superyo, del ideal del yo, del carácter y de la identidad (Freud 1983a, 1983b, 1983c, 1983d, 1983e, 1983f, 1983g, 1983h; Sandler, 1986). Constituye la forma más primitiva de relación objetal previa al verdadero reconocimiento cabal del otro, (Panceira, 1997; Sandler, 1986; Winnicott, 1971, 1979, 1992, 1993), además de implicar un vínculo afectivo con ese otro cuya conducta es imitada (vínculo con un objeto del yo) y a quien se toma como un ideal (Sandler, 1999). Permite además establecer una corriente de simpatía por la cual somos capaces de situarnos en el lugar del otro (Panceira, 1997). Se trata, según Ionescu, Jacquet y Lhote (2001) de un fenómeno que constituye el punto de partida de una relación objetal, al mismo tiempo que de una defensa esencial contra la ausencia de objeto. Es un proceso inconsciente, aunque puede tener componentes conscientes: el sujeto modifica sus patrones de conducta y sus respectivas representaciones del self de forma tal que siente ser semejante a las representaciones del objeto, confundiéndose con ellas. Algunas identificaciones se prueban y se descartan porque demuestran ser impracticables o son objeto de castigo, otras se conservan como parte del propio repertorio, adecuadamente modificadas e integradas en el curso del tiempo en una identidad viable propia.

A partir de todo lo revisado hasta aquí, vamos a entender la identificación como un proceso psicológico, esencial para la constitución y diferen- 
ciación de la personalidad, mediante el cual un sujeto se transforma total o parcialmente sobre el modelo de otro, tomando prestada la identidad de algún otro, o aspectos de esta, pudiendo, en algunos casos, llegar a fusionar o confundir su identidad con algún otro.

En cuanto a los procesos de identificación específicamente en el actor, si nos remontamos a la historia del teatro, encontramos algunos datos relevantes para nuestro tema, como el hecho de que si bien el teatro en la actualidad no tiene una finalidad terapéutica, históricamente sí, ya que se trataba de un fenómeno catártico (Alford, 1992). Por otro lado, recordemos que en sus inicios el teatro se representaba con máscaras, lo cual nos remite a una identidad de fachada. Otro dato importante es que en la época shakesperiana, los hombres representaban personajes femeninos, funcionando esto como un self también de fachada.

Más recientemente, Lowenfeld (1941) ha sugerido que las experiencias traumáticas tempranas son precondiciones para la actividad creativa, ya que estas producen una necesidad duradera de repetir de manera activa lo que se experimentó originalmente de forma pasiva.

Para Weissman (1961), la naturaleza del trabajo del actor le permite a este satisfacer su necesidad de aparecer ante una audiencia. Sus personajes le dan la oportunidad de buscar una autoimagen, una autorrepresentación que produce en él un equilibrio homeostático. La forma universal de comunicación placentera entre la madre y el infante, nos dice Weissman, tiene la categoría de representación de un rol. La madre actuará el papel de la madre, con arrullos y gestos, y el infante a su vez imitará a la madre para complacerla. En este sentido la madre es la autora y directora que crea un personaje para el infante y se lo enseña. Este proceso sería una forma temprana de identificación, que precede al desarrollo de relaciones objetales más firmes y a la subsecuente pérdida de objeto. Si las gratificaciones de la madre van más allá de las necesidades afectivas reales del bebé, tenderá a prolongar el periodo de narcisismo primario y a preservar la omnipotencia mágica de una organización relativamente indiferenciada. En el deseo alucinatorio del actor de revivir la relación temprana con la madre, la audiencia no representa una relación de objeto que pueda ser perdida, sino más bien una parte del self que estará faltando. El actuar un rol para una audiencia puede así representar el punto de fijación evolutiva de la fusión entre el self y el no self. La fijación a tal nivel puede resultar también, por supuesto, de la deprivación de la participación de la madre en el juego del infante. El actor busca en la audiencia un objeto primario, al que incluso antropomorfiza. Si lo encuentra, se refuerza su autoimagen pero no se establece una relación de objeto. El actor tiene así una aventura amorosa con la audiencia. 
Laura Achard (1962) ha trabajado el tema de las defensas implicadas en la creación de un personaje. Después de participar como observadora en ensayos de grupos teatrales, llegó a la conclusión de que, en el proceso de creación de un personaje, el mecanismo que predomina es la identificación introyectiva, encontrándose también la identificación proyectiva, aunque siempre en combinaciones, nunca en formas puras. Para ella, en un primer momento, cuando al actor se le comunica que va a representar un rol, proyecta aspectos corporales y psíquicos en el imaginario personaje de manera casi automática, midiendo las posibilidades de conexión o desconexión con este, y mezclándose las características de ambos.

En un segundo momento se da una identificación introyectiva parcial que se inicia con frecuencia tomando al cuerpo como referencia. En general, se introyectan aspectos corporales del personaje y se siente que este empieza a cobrar solidez y a adquirir existencia. Luego aparecen otras identificaciones parciales vinculadas a alguna vivencia o emoción, empezando a bosquejarse una figura que pronto tendrá vida propia. Estos dos primeros momentos se cumplen siempre. Sin embargo, solo a veces sucede que el yo del actor tiene que hospedar a otra figura más, lo cual correspondería a un tercer momento. Esto sucede cuando se preparan dos personajes a la vez en una misma obra o en diferentes proyectos. Aparentemente, el resultado final es siempre satisfactorio y gratificante. Se experimenta inicialmente una ansiedad que tiene que ver con el desconocimiento parcial de lo que se va a introyectar. El estar siempre creando y poseer más de dos personajes es visto como fuente de vida, constituye un mecanismo reasegurador contra fantasías de vaciamiento y destrucción. Siempre hay alguien que lo está habitando, aunque a veces ese alguien represente un aspecto temido o rechazado.

En la forma siguiente de identificación se dan distintas reacciones frente a un personaje que puede significar aspectos del yo censurados y reprimidos o la realización de fantasías inconscientes muy temidas. Al inicio puede haber resistencia, el actor buscará algo positivo en el personaje que le permita justificarlo y facilitar su incorporación. A veces lo encontrará tan distante, tan desconectado que se rechaza en primera instancia. Aceptar un personaje perverso o malo sería el equivalente a vivir la perversión o las fantasías inconscientes más rechazadas. Parecería que el riesgo es que fantasía y realidad tiendan a fundirse y aparece la necesidad imperiosa de protegerse y ponerse a salvo de lo temido. Proyección, negación y aislamiento son los mecanismos predominantes. También puede haber un regodeo y aceptación total del personaje rechazado, lo cual se observa en actores con un yo flexible, un superyo 
poco rígido y que poseen además talento y 'oficio'.

Un quinto momento, donde Achard (1962) encuentra la identificación introyectiva invasora con elementos de proyección, parece depender en parte de la índole del personaje, generalmente figuras de gran poder, encanto o seducción para el actor. Esto puede ser consciente o inconsciente. Esta identificación proyectiva invasora se produce como expresión fallida de un diálogo, duelo a veces, simbiosis otras, entre el actor y la figura introyectada, hay una primacía de uno sobre otro, no ya en la representación sino en la vida misma, y el equilibrio deseable queda roto parcialmente. El yo del que representa regresa a una etapa esquizoparanoide. Disociación, negación, idealización, omnipotencia, proyección, son los mecanismos que se observan en la identificación proyectiva invasora. El yo del actor se disocia, niega su unidad, idealiza al objeto introyectado, lo vive en forma omnipotente y lo proyecta afuera, invadiendo esta relación simbiótica otras esferas en un afán de mostrar su fuerza y grandeza. Hay, pues, un fracaso temporario del auténtico proceso de creación y de la identificación introyectiva final, la cual sería integradora y armónica. Si se lograra más bien esta última fase, el actor ama al personaje, siente que le pertenece. Se ponen en marcha mecanismos reparadores y una relación simbiótica delimitada y fuerte. El personaje ha penetrado y rea- firmado su poderío y fuerza vital. Es una totalidad, vive como tal. Es una síntesis armónica del yo con 'él'.

Achard (1962) puntualiza que habla de relación simbiótica entre dos porque ahora estos constituyen entidades diferentes que se enriquecen mutuamente y no pueden vivir separadas. En este periodo, el objeto introyectado es fuerte, coherente, vibrante y sensible. Posee gran independencia y libertad interior. Todas estas cualidades hacen que pueda proyectarse con extremada precisión y justeza y ofrecerse al espectador. Mientras esto acontece, el yo del actor sigue oscurecido, en la sombra, pero experimentando una gran felicidad. Es como un momento mágico, cuya ubicación cronológica es difícil, influyen el actor, la obra, el acuerdo o desacuerdo con el director, etcétera. En términos generales, este logro llega después del estreno; y no siempre se alcanza. Si no se llega a esta meta, aparece la frustración, más allá del aplauso o de las buenas críticas; hay una disconformidad, pues el actor no vive su personaje en forma auténtica.

Sandler y Sandler (1999) plantean que los límites entre la percepción del self y del objeto no debería considerarse como algo inamovible, pues estas no son entidades fijas que una vez formadas permanecen en un lugar. Existe una función que establece límites, para diferenciar al self del otro, una función de desidentificación que nos dice hasta dónde somos nosotros y dónde empie- 
za el otro. Los límites pueden relajarse y volver a situarse con rapidez. Existe una fluctuación inconsciente constante respecto de la extensión y la fuerza con que se restablecen. Esta fluctuación del límite entre el self y el otro posibilita el proceso inconsciente de identificaciones primarias, lo cual permite que el poeta (y por supuesto, también el actor) proyecte y se identifique, simultáneamente con aquellos aspectos de su self y de los objetos, experimentando las relaciones entre ellos, tal y como las representa en su obra. Es un proceso que le permite modular y refinar sus personajes de forma significativa y satisfactoria. El espectador obtendría placer de la obra que observa utilizando los mismos mecanismos de identificación primaria. Así, podrá identificarse con diversos personajes, defenderse de las identificaciones que no le acomodan, y acomodarse identificándose con personajes que le son más fáciles de aceptar.

Nuetzel (1995), psicoanalista y director de teatro, nos recuerda que hoy en día es común escuchar a psicoanalistas hablar de su trabajo en términos teatrales, tales como el "escenario psicoanalítico", o el "teatro de la mente", (p. 346). Podemos recordar también otros términos aún anteriores, como los términos freudianos de "escena primaria". Esto se debe a que la situación y el proceso analíticos implican una dramatización de aspectos de la historia de la vida psíquica del paciente, creada y puesta en escena en conjunto con, y di- rigida por, el analista. Nuetzel observó durante una investigación, que el director de un montaje teatral tenía que hacerse cargo de transferencias individuales y grupales, manifestadas en un fenómeno que describió como "neurosis de producción". Respecto de estos fenómenos se preguntaba si la puesta en acto colectiva e inconsciente de dinámicas emocionales derivadas de la obra en producción por el director y el elenco era un fenómeno inevitable para la puesta en escena final.

Concluyó Nuetzel (1995) que del mismo modo en que los pacientes desarrollan nuevas versiones de sus enfermedades a través de la neurosis de transferencia, así también nuevas versiones de obras para presentaciones teatrales pueden desarrollarse a través de las neurosis de producción. Todas las dinámicas de las interacciones entre actores y entre ellos y el director tenían las dimensiones de una transferencia resistencial. Lo sorprendente, afirma Nuetzel, era la verificable dimensión inconsciente de estos fenómenos, dado que estos episodios eran reconocidos solo en retrospectiva.

En otras palabras, lo que plantea Nuetzel (1995) es que tanto actores como directores habitan el texto de la obra, y el texto los habita a ellos. Durante el proceso de producción esto se manifiesta en interacciones emocionales entre los actores y el director. Estos actings en el proceso de creación teatral le permiten a los actores y al director encontrar 
puntos de identificación entre el texto, ellos mismos y los otros.

En cuanto a la identificación en la teoría y la técnica teatral, deseamos describir sucintamente lo que plantea Stanislavski (1977, 1979, 1980, 1989). Para él, el actor puede ser ayudado a pensar realmente en el escenario, en lugar de pensar de una manera simulada. Para ello estableció ejercicios, siendo la "memoria emotiva" una de las técnicas. Una vez que el actor comienza a pensar, comienza la vida, y entonces ya no puede haber imitación, la cual, desde su punto de vista, es indeseable en un escenario. Para Stanislavski el talento de un actor pasa necesariamente por estar dotado de sensibilidad y emocionalidad para responder a los estímulos, reales o ficticios. Si no puede responder emocionalmente, no puede ser actor. Sin embargo, afirma, la sensibilidad y la respuesta emocional de un actor podrían convertirse en un problema si este no puede controlarlas, y aquello mismo que podría ser bueno para él, es un obstáculo. Esto se desprende directamente de la paradoja que ya en el siglo XVIII había planteado Diderot (Strasberg, 1989): el actor solo puede conmover al público si él mismo no se deja conmover.

Otro problema que identifica Stanislavski (1989) es la anticipación, a la cual ve como una "enfermedad" para el trabajo escénico. El actor sabe que está en un escenario para hacer exactamente lo mismo que hizo el día anterior y conoce el texto de memoria. Sabe cosas que el personaje no puede saber, $y$ por lo tanto tiende a dejarse influir por ese conocimiento, a representar el resultado, más que a hacer que este sea el punto final de un proceso. El personaje, en cambio, no sabe lo que va a pasar. La situación escénica debe parecer que no ha tenido lugar antes, que nadie la ha representado antes. Habla Stanislavski de un despojamiento biográfico de los actores, del abandono de estos a otra vida y otra historia, de prestar el propio cuerpo para que en él viva el personaje.

Sonia Moore (1991), estudiosa del método de Stanislavski, nos dice que cuando un actor está inspirado, sus emociones fluyen, sus acciones son reales a la vez que teatrales, su actuación es clara para la audiencia, y el actor se reencarna en el personaje. Pero esta inspiración no es común, aunque se trate de grandes actores, porque por lo general el actor se siente empujado a aparentar, a forzar emociones, lo cual hace que su trabajo resulte mediocre. La dificultad mayor para un actor, nos dice, es deshacerse de eso, y en ese sentido la misión de Stanislavski fue perseguir y analizar el fenómeno de la inspiración en el escenario, de modo que cualquier actor capaz pueda ejercer control consciente sobre ella.

Stanislavski pasó cuarenta años de su vida, nos recuerda Moore (1991), ideando ejercicios para que el actor pueda funcionar con naturalidad en el 
escenario, controlando a la vez sus mecanismos emocionales inconscientes. No se trata de, simplemente, hacer aparecer las emociones del actor, sino que además estas deben estar adecuadas a las circunstancias del personaje. En la vida experimentamos emociones porque hay circunstancias reales que las movilizan, pero en el escenario nada es real. Y el actor tiene que tener plena conciencia de ello. La emoción en el escenario es diferente a la emoción de la vida, porque el actor lleva una doble existencia, en donde es el personaje, pero a la vez es el actor que crea al personaje. El actor en el escenario vive una emoción "repetida", que es diferente a una emoción "primaria", siendo que la primera no surge por algo real, sino que el actor la hace surgir porque tiene un registro de ella, y por lo tanto no lo absorbe enteramente. El actor posee todas las emociones que necesita antes de representar a un personaje, preservadas en la "memoria emocional", donde las emociones están purificadas por el tiempo, y por lo tanto es posible "poetizarlas".

Recapitulando la evolución del método de Stanislavski, Moore (1991) nos dice que una vez que él descubrió la importancia de la memoria emotiva, sus ejercicios se volvieron puramente psicológicos: sus actores llegaban al teatro horas antes de la representación para aislarse y poder concentrarse en alguna tragedia o circunstancia personal, y en los ensayos el análisis del texto y las discusiones en torno a él duraban meses. Luego de años de trabajar así, Stanislavski se dio cuenta de que en vez de liberar las emociones de sus actores, había paralizado sus subconscientes. Los actores parecían confundidos en lo personal, en algunos casos muy perturbados, y en el escenario mostraban "naturalidad", pero no teatralidad. Stanislavski mismo reconoció que esta parálisis era consecuencia de haber usado en su método procedimientos puramente psicológicos, y que todo esto deterioraba la vida personal del actor, así como su arte. Este período del trabajo de Stanislavski ha sido considerado en Rusia como el más peligroso de la historia del Teatro de Arte de Moscú, por la cantidad de casos en los que los actores se veían afectados en su funcionamiento nervioso.

Para Moore (1991) el problema principal en la aplicación del método de Stanislavski es que la mayoría de actores que lo siguen lo hacen parcialmente. Para unos, dice, familiarizados con las técnicas de relajación, el secreto de una buena actuación es relajarse. Otros, familiarizados con el periodo de memoria emotiva en su trabajo, asumen que esa es la clave. En estos casos, un periodo de los experimentos stanislavskianos se convierte en el sistema completo, cuando cada una de estas técnicas experimentales desilusionaron a Stanislavski en la medida en que ninguna de ellas por sí sola era suficiente, motivo por el cual siguió buscando un 
"camino consciente hacia el inconsciente". Stanislavski estaba convencido de que trabajar con el inconsciente todo el tiempo era un error fundamental, y una de las peores distorsiones de la actuación.

En esta búsqueda, refiere Moore (1991), los experimentos de Stanislavski coincidieron en un momento histórico con los de Iván Pavlov, en cuanto a la conexión entre la experiencia interior y su expresión exterior. Stanislavski, al igual que Pavlov, llegó a la conclusión de que la mente y el cuerpo están tan íntimamente conectadas que se estimulan e influencian mutuamente; todo proceso mental es inmediatamente transmitido al cuerpo en una expresión visual, por lo cual la conducta humana es un proceso psicofisiológico ininterrumpido. A partir de este descubrimiento revirtió sus enseñanzas previas y empezó a poner énfasis en el lado fisiológico del proceso psicofísico, dando lugar al Método de las Acciones Físicas, el cual no es ya solo un periodo, sino su legado integral al teatro.

Finalmente, en su método, Stanislavski (1989) revirtió el proceso mismo de la vida: ante un evento experimentamos una emoción, y nuestro cuerpo la expresa. En el teatro, el evento nunca sucede en la realidad, pero a través de controlar el cuerpo, de identificar determinados músculos, un actor puede conectarse con una emoción. En el escenario se deben identificar los músculos conectados a las experiencias inte- riores con el fin de movilizar y generar el torbellino emocional dentro de uno, alcanzando un compromiso psicofísico. Si se logra esto todo el organismo estará involucrado -los sentidos, la memoria, la voluntad, las emociones, el cuerpo-, y el actor se desenvolverá en el escenario como un ser humano real. Por supuesto, esto implica mucho entrenamiento físico y una sensibilización psicofisiológica. Así, en el método final de Stanislavski el actor se concentrará en la revelación de la psicología individual del personaje a través de la organicidad.

Queremos resaltar aquí que el método de Stanislavski facilita, evidentemente, los procesos de identificación. Como plantea Halprin (2003), nuestro cuerpo contiene nuestra historia de vi$\mathrm{da}$, de la misma forma en que contiene músculos, huesos, nervios, órganos y sangre.

El Método de las Acciones Físicas fue considerado por su creador como la esencia de su sistema de entrenamiento. Y la memoria emotiva fue vista finalmente como un reservorio en donde las experiencias emocionales vividas en lo personal han dejado una huella en nuestro sistema nervioso central, haciendo que nuestros nervios participen de manera más sensible. Finalmente, el concepto de conjunto también cobró importancia, ya que se trata de que el actor reaccione psicológica y fisiológicamente a las acciones de otros personajes. Es más, el público mismo, del 
cual el actor no puede perder conciencia, es un cocreador de su trabajo, en la medida en que le da pistas de su desenvolvimiento.

En la actualidad, el Actor's Studio es la academia de actuación que proporciona el entrenamiento más reconocido y seguido por actores de todas partes del mundo. Este es el método de Lee Strasberg, seguidor de las ideas de Stanislavski. Para Strasberg (1989), la naturaleza humana del actor no hace posible su grandeza, sino que es también la fuente de sus problemas. Nos dice que un actor puede tener dificultad de expresarse, a pesar de su habilidad técnica, a causa de su vida emocional o de los problemas inherentes a su existencia, y sugiere entonces que, en primer lugar, el actor debe tratar de aliviar cualquier dificultad inherente de sí mismo que niegue su libertad de expresión y bloquee sus capacidades. Si no entendemos mal, básicamente lo que pide es que, al igual que un analista $o$ terapeuta que debe ser analizado para optimizar y cuidar su instrumento principal, su propia persona y emociones, el actor debe pasar también por un proceso de análisis, o al menos de autoanálisis.

Al igual que Stanislavski, Strasberg (Hethmon, 1972) opina que el actor no necesita imitar al hombre. El actor mismo es un ser humano y puede crear algo de sí. Solo en el teatro, nos dice, tenemos las emociones del alma, el espíritu, la mente y los músculos del artista como material artístico. Sin embargo puntualiza:

... no se trata de no saber lo que uno hace sino de emplear las experiencias que hemos almacenado en el inconsciente y que no podemos fácil o rápidamente tocar de una manera consciente (...), emplear el conocimiento que funciona en sueños, donde a veces salimos con cosas que aparentemente no tienen sentido, con cosas que ocurrieron hace muchísimos años pero que hace tiempo supusimos haber olvidado (p. 59).

Nos dice Strasberg (Hethmon, 1972) que hay dos tipos de actores: aquellos que, conservando su personalidad se introducen en el personaje, y aquellos que necesitan sentir la máscara, $y$, cuando se sienten protegidos por ella, logran hacer lo que quieren. Para Strasberg se trata de dos técnicas de actuación entre las cuales cada actor elegirá.

A continuación presentamos algunos de los resultados obtenidos de las entrevistas realizadas para este trabajo, y su interpretación. Para tal propósito hemos clasificado los datos en tres ejes temáticos. El primero y más importante aborda los procesos de identificación entre el actor y sus personajes, privilegiando el hecho del establecimiento de un vínculo entre el actor y su personaje. Se explora en esta línea la naturaleza de dicho vínculo, las similitudes y diferencias encontradas entre el actor y los personajes, así como los momentos de confusión suscitados, los mecanismos defensivos empleados para controlar tal confusión, y por último los niveles de conciencia encontrados. 
Inmediatamente pasamos, en un segundo eje, a un análisis más personal del actor mismo: sus motivaciones vocacionales, tanto infantiles como actuales, y datos de su historia que resultan significativos para las identificaciones encontradas. Finalmente pasamos al tercer eje, en el cual analizamos el paso de las identificaciones encontradas desde el ámbito propiamente escénico al de la realidad personal del actor, sus vínculos con otros actores, con otros personajes, con el público, y con el director.

\section{LOS PROCESOS DE IDENTIFICACIÓN}

\section{ENTRE EL ACTOR Y EL PERSONAJE}

Los entrevistados opinaron que para poder representar satisfactoriamente un personaje, este tiene que parecerse, en alguna característica esencial, al actor. No se trata de características exteriores tanto como de características interiores, más o menos escondidas:

Los personajes shakesperianos (...) contienen todo lo que una persona puede contener, el extremo malo como el extremo bueno, el extremo incorrecto como el extremo correcto, inclusive el extremo masculino como el extremo femenino. Entonces va a contener de todas maneras algo tuyo, (...), todos van a tener algo de ti. Y no se van a parecer a ti. Pero en lo esencial van a ser parecidos a ti (Manuel).

Es imposible que un buen personaje no tenga algo de ti. Entonces, para mí es muy difícil decir me tengo que transformar en una persona que no soy (...). $\mathrm{O}$ sea, si yo hago de vieja, (...) la vieja va a seguir siendo como yo. Solo que con más años y reumática. (Camila).
Si bien para Achard (1962) se trata de proyecciones que automáticamente el actor coloca en el personaje que está creando, es evidente que lo proyectado es percibido y puede a veces generar incomodidad. Se trataría, entonces, desde nuestra perspectiva, de identificaciones proyectivas, más que de proyecciones, pues el actor observa, en algún nivel, coincidencias con el personaje, coincidencias que, sin embargo, prefiere racionalizar (Manuel: "los personajes shakesperianos son extraordinarios porque contienen todo"). Esta característica de la identificación proyectiva, a diferencia de la proyección pura, fue ya planteada por Rosenfeld (Grinberg, 1978), quien hablaba de un alivio al percatarse el sujeto, inconscientemente, de que lo proyectado le pertenece, pues es así que puede sentir que se está deshaciendo de ello. Kernberg (1987) también planteó que la identificación proyectiva se caracteriza por el hecho de que el sujeto sigue experimentando el impulso proyectado, y de allí la necesidad de controlarlo en el otro.

Se establece, por otro lado, una diferencia entre los personajes "bien escritos", aquellos que ya expresan explícita o implícitamente los rasgos y contenidos del personaje, y aquellos a los que el actor tiene que "inventarle" características o contenidos (evidenciando aún más la proyección) para que resulten "creíbles" o "redondos", como se suele decir entre actores. Eviden- 
temente, si aquello proyectado coincide con la realidad, va a resultar mucho más fácil para el sujeto sentir que finalmente no le pertenece en tanto pueda ser controlado en el otro; en cambio, si lo que se proyecta no se ajusta a las características del otro en quien se proyecta, el fracaso de la identificación proyectiva es mayor, y por lo tanto se siente mayor incomodidad. Este es el principio, además, por el cual se establece dentro del contexto terapéutico, la neutralidad, pues cuanto menos conozcamos del otro, más pantalla en blanco podrá ser este, evidenciándose más claramente que los contenidos proyectados pertenecen a quien los proyecta, generándose así mayor ansiedad.

Por otro lado, se plantea el reconocimiento de que el actor suele tener un yo flexible al estar en mayor contacto con contenidos interiores diversos, como planteó Eduardo: "El actor es una persona psíquicamente... plural..."

Fenichel, nos recuerda Weissman (1961), se había ya cuestionado si el mejor actor no sería aquel capaz de interpretar cualquier rol en virtud de sus grandes posibilidades de identificación. Si bien Fenichel asociaba este fenómeno a una falla de integración en la identidad, nosotros lo vemos más bien como una manifestación de flexibilidad yoica. Nos preguntamos, por ejemplo, si el actor en principio es más capaz que otras personas de identificarse con diferentes aspectos de otros, porque ya están en él, o si la diferencia es- tá dada más bien en que el actor tiene menos temor que los demás para evidenciar esos aspectos, o que quizás simplemente ha descubierto que el teatro es un canal socialmente aceptado para tal exteriorización, lo cual, como veremos más adelante, es bien reconocido por los entrevistados. Por otro lado, como hemos destacado, la identidad, desde una concepción psicoanalítica, no es una estructura estable e inflexible, como evidencia Goffman (1959), para quien no tenemos una identidad, sino varias (pública, privada, etcétera).

Nuetzel (1995) planteó que durante los ensayos de un montaje teatral los actores parecían habitar lúdicamente el texto de la obra y el texto habitarlos a ellos. En nuestra opinión, el actor prefiere personalizar el fenómeno y sentir que habita al personaje que representa, incluso prefiere esto antes que sentir que es el personaje quien lo habita a él. Tal vez esto le resulta menos amenazante, pues conserva el control, a la vez que evita sentirse invadido. Fonagy y Target (1996a, 1996b) decían que el niño va descubriendo su propio funcionamiento mental a través de explorar la mente del otro. Esta exploración constituye la formación de una perspectiva que delimita los límites propios y los del otro, estableciéndose una representación mental separada del sí-mismo. Desde el punto de vista del actor, esto puede ser tranquilizante, pues, si los límites son claros, es menos riesgoso 
aventurarse a una identificación que, creativamente, implique una regresión a la fusión.

Parecería, pues, estarse reconociendo la proyección de aspectos propios, a la vez que se va esbozando una introyección de los contenidos, nuevamente en concordancia con lo que sugiere Achard (1962). Todo esto tiene que ver, probablemente, con el hecho de que el actor busca identificarse consigo mismo, como veremos más adelante en mayor detalle, en tanto la actuación es una búsqueda y un descubrimiento personal. Estas identificaciones, además, tienen que ver con un proceso en el cual uno se va acercando a uno mismo:

Mis personajes tienen que tener mi voz, mi cuerpo, mi experiencia, todo lo que yo pueda prestarles, mis recuerdos, mis penas, las cosas que no quiero destapar, o las cosas que hubiera querido vivir y nunca viví, es el momento de ver cómo sería si lo hubiera vivido... (Carlos).

En esta autoexploración, vivida como la exploración de un otro, el actor llega a acercarse también a aspectos reprimidos:

... de pronto te hacen descubrir aspectos que tú no crees tener, (...) que nunca te han salido en la vida real, y de pronto te salen, y a veces con un cierto placer, un nivel de maldad, de sadismo gozoso, (...) cuando tú sabes positivamente que en la vida real no eres así... cuando el proceso lo permite, y ojalá lo permitiera siempre, se producen descubrimientos nuevos (Camila).

El actor hace, pues, que el personaje cobre vida: no es el personaje el que le ofrece cosas, sino al revés. Esto, como hemos visto, resulta tranquilizante para el actor, pues le permite una cierta omnipotencia que le otorga el control:

Mis personajes no existen (...). Es decir, Hamlet no existe, pues. Y no existe porque está escrito. (...) Entonces el único que está vivo eres tú. El actor, no el personaje. (...) Y por lo tanto el entrenamiento de una escuela es darle la capacidad al actor para que se encuentre consigo mismo, para que aumente su registro corporal, vocal, actoral, y pueda, con toda esa materia, hacer que algo viva (Roberto).

En este sentido queremos recordar, una vez más, que tanto Winnicott (1971, 1979, 1992, 1993) como Fonagy y Target (1996a, 1996b) afirman que para delimitarse, el bebé necesita que otros se presten para la exploración y el juego. El personaje se presta para esta aventura. Al proyectar en el personaje aspectos propios del actor, más o menos escondidos -y recordemos aquí, además, que Piaget (1969) mencionó ya que solo se puede reproducir lo que se lleva dentro- el actor poco a poco va percibiendo al personaje como un ser con vida propia; pero también empieza a verse a sí mismo. El personaje será visto como un reflejo personal que debe, sin embargo, independizarse. De la comunidad inicial empiezan a establecerse diferencias, que tienen que ver más con las actitudes manifiestas y exteriorizables que con los contenidos y características esenciales.

Este último aspecto resulta importante en la medida en que pareciera ser 
fundamental para el actor resaltar esa diferencia como un indicador de distancia. Esas discrepancias, sugerimos, le permitirían al actor sentir que él mismo es un ser diferenciado. Si bien este proceso es sentido como que es el personaje el que cobra vida, podría estar en juego la necesidad de sentir que es el actor mismo el que puede mantener su individualidad. Aquello proyectado quedó fuera, y con ello el sujeto se puede distanciar:

He dicho cosas, haciendo el personaje, que me he dado cuenta después, que el pata tiene vida propia, o sea, yo no lo hubiera dicho así (...) en una situación igual, no te lo hubiera dicho de esa manera, o no hubiera hecho ese gesto, o no hubiera hecho esa inflexión, sí, sí cobran su vida propia (Carlos).

Para lograr que un personaje cobre vida, parecería, además, que el actor debe eventualmente permitir, durante un tiempo, que este lo habite, evidenciándose en un segundo momento del proceso con más claridad la introyección. Una vez que el actor se ha asegurado de establecer límites entre él y su personaje, puede entonces, con una mayor sensación de seguridad, permitir que el personaje lo habite. Creemos que en este momento puede hablarse ya de incorporación, en el sentido en que lo planteó Klein (Hinselwood, 1989), en donde hay una fantasía de absorción corporal en la cual el objeto introyectado se siente activo dentro de uno:
... ideas, cosas o formas que te van pasando por la cabeza, y tú estás seguro, convencido de que esas son las que tienen que ser, esa es la forma en que tienes que hablar, esa es la forma en que tienes que caminar, esa es la forma en que tienes que hacer la flexión, esa es la forma en que tienes que mirar... tienes la seguridad de que el personaje es así... (Carlos).

Como hemos anotado, Achard (1962) plantea que al inicio se dan proyecciones e introyecciones parciales que poco a poco se van integrando. Ella sugiere la identificación introyectiva como mecanismo principal de la relación entre actor y personaje, aunque la identificación proyectiva también aparece, siempre combinándose ambas. Klein (1955), por su lado, describía la identificación introyectiva como la posibilidad de identificarse con algún objeto interno, llegando el sujeto a ser como él (en el caso del actor, a través del personaje), reconocer por lo menos que existe una comunidad, y al observarlo se genera una experiencia de identidad. Existe, entonces, un doble movimiento de introyección y proyección:

... uno viste al personaje, lo trabaja, hace emerger cosas para el personaje, pero también uno se viste de él. (...) uno se cubre, como que se tapa del frío y de la intemperie y del posible ataque de fuera... (Eduardo).

En este ejemplo se evidencia la necesidad sentida por el actor de defenderse. Lo proyectado es sentido como peligroso o persecutorio, pero a la vez 
aspectos de aquello proyectado son idealizados y reintroyectados buscando una cierta omnipotencia. Más adelante retomaremos el tema de las defensas.

Si bien hasta aquí hemos resaltado principalmente el primer movimiento, en las viñetas siguientes se atisba más bien el segundo, el de introyección. Por su parte, Laplanche y Pontalis (1983) ponen énfasis en la gradual constitución de la personalidad, mediante series de identificaciones, siendo que cada experiencia o vínculo transforma $o$ consolida una parte del mundo interno. Es así que el actor podría irse redescubriendo a través de su trabajo, enriqueciendo su conocimiento de sí mismo, y consolidando aspectos personales.

Pero el fenómeno puede ser también percibido desde otra perspectiva, la de ir armando una personalidad en base a los personajes que se han ido representando en el tiempo. Se trataría de personalidades vacías, que asumen un papel porque este les otorga una identidad. Como planteaba Winnicott (Panceira, 1997), sucede a veces que, con el afán de ser aceptado por otros, se instala un sí mismo engañoso, una imagen falsa, con poca conciencia de las verdaderas motivaciones. Los entrevistados afirman que algunos actores se valen más bien de sus personajes para ir armando su propia personalidad, aspecto que los actores mismos asocian con cierta perturbación, por lo cual, en ge- neral, ofrecieron ejemplos de otros actores, más que sobre sí mismos:

Patricia (...) se identifica a través de cómo la ven los demás. Crea una imagen, y tiene la imagen de sí misma como rebote de la imagen... a través del comportamiento que los demás tienen con ella como consecuencia del comportamiento de ella... una imagen de... lideresa, y en realidad Patricia es una mujer muy insegura, creo que es el self que ha adoptado, para equilibrarse un poco (Eduardo).

Hasta aquí podemos afirmar que existe una comunidad de características entre actor y personaje, una necesidad de diferenciación también, una autoexploración a través de un "otro" -el personaje, un otro creado por el autor-. Existe entonces un vínculo.

Ahora bien, las identificaciones pueden ser placenteras o displacenteras, dependiendo del nivel de conflicto que se presente, si la característica en cuestión es un aspecto rechazado o no aceptado del actor, con lo cual incluso su trabajo se va a ver afectado en su eficacia. Es decir, no se le puede "poner" algo al personaje si el actor está en conflicto con ese algo, pues está presente aún el reconocimiento de que aquello es también propio. Como hemos visto, al no tratarse de una proyección pura, de la cual el sujeto podría deshacerse por completo, hay personajes que un actor no puede representar porque le produciría fracturas y ansiedades muy fuertes, sobre todo si se trata de contenidos extremos: 
Sí, eso sí me costó horrible... porque yo no soy una persona bonita, definitivamente, eso yo lo tengo claro (...). Brillar, como quería la directora, no lo iba a poder hacer. (...) Porque ella necesitaba que yo me sintiera bonita... (Camila).

Se va logrando, sin embargo, como sugiere Achard (1962), una aceptación del personaje a través de mecanismos reparadores, y eventualmente actor y personaje llegan a constituirse en dos entidades separadas que se enriquecen mutuamente. Podemos agregar que este enriquecimiento se da porque aparece también una aceptación propia a través del personaje, como plantea Carlos: "Es importante querer al personaje, si no, no lo puedes hacer bien".

En todo este proceso, las confusiones que las coincidencias suscitan, parecen darse, efectivamente, así como la pérdida de control. Esto es explicado por Achard (1962) como un fracaso en la identificación introyectiva integradora final, la cual, si es lograda, es sentida como satisfactoria en una vivencia de plenitud con el trabajo creativo realizado. Pero si esto no sucede, la identificación introyectiva es sentida como invasora, rompiendo el equilibrio y haciendo que el actor regresione a una etapa esquizoparanoide:

... en un ensayo ya no quería seguir, porque yo sentía que lo que estaba pasando era de verdad, que había matado a alguien, y ahora estaba aterrado de lo que acababa de hacer. La sensación era muy extraña, porque yo sabía que no había pasado, no estaba fuera de mí. Pero la carga emotiva era tan fuerte... yo sen- tía... tenía toda la culpa, toda la pena, todo el miedo y toda la soledad de ese personaje (Manuel).

Cuando decían algo del personaje, me afectaba en la medida en que sentía que habían hecho un casting y yo me acercaba al personaje, y por lo tanto me acercaba también a los insultos recibidos (ríe), entonces sabía que algo había también de esos insultos para mí (Carlos).

Del material recogido observamos que también se evidencian defensas en el trabajo actoral. El hecho de que el actor se defienda más o menos rígidamente va a depender tanto de la cercanía con el personaje y del hecho de que se rechace una determinada característica de este, como de las características defensivas inherentes a la personalidad del actor. Achard (1962) también observó el establecimiento de defensas en el proceso creativo, afirmando que aquello de lo que se defiende el actor es de las ya mencionadas identificaciones introyectivas invasoras. Para ella, las defensas más utilizadas son la disociación, la negación, la idealización, la omnipotencia y la proyección: el actor se disocia, niega su unidad, idealiza al objeto introyectado que se siente omnipotente y lo proyecta afuera. En el material recopilado en base a nuestras entrevistas encontramos que, en general, en la actuación parecería que la defensa más común evidencia una toma de distancia, generalmente a través de la caracterización, de la indiferencia (ais- 
lamiento), o el uso del humor. ${ }^{1}$ A continuación presentamos algunos comentarios de los entrevistados:

Hay actores que no pueden dejar de caracterizar. (...) Esa caracterización te esconde (Camila).

Si lo hacía de verdad, y realmente hacía que esa obra cobre la dimensión trágica que tenía... me cagaba yo. Y lo hice un personaje cómico, en una situación cómica. Y ahora me doy cuenta de que no era así... (Roberto).

En otros casos es la... aparente... indolencia. Juan, por ejemplo, hace las cosas como si no afectaran. (...) Los aligera, digamos, para no complicarse la vida (Eduardo).

Otras defensas comunes son la racionalización o la intelectualización, en donde todo lo que hace el personaje tiene que estar justificado, o las defensas que implican convertir los contenidos en lo contrario, o la omnipotencia, o agregarle al personaje características que equilibren o den un balance hacia el extremo opuesto. En este grupo de defensas lo que parece estar buscando el actor no es tanto la distancia como el mantener el control:

Si la relación ficticia es conflictiva, creo que lo que tiende a pasar, es más bien lo contrario. Y si pienso un poco, digo, por defendernos pues a nosotros mismos. $\mathrm{O}$ sea, si no lo cogemos en el opuesto, esto va a estar hasta las pelotas. O justamente hacemos catarsis y lo único que nos queda después de esta crisis es suspirar hondo, y abrazarnos y felicitarnos. (...) En una escena con Julito, el tipo me iba a matar, y yo también lo quería matar, y yo temblaba, y después ah, acabamos así, elogiándonos... (Manuel).

... el galán no era galán, al malo le encuentras la bondad, al bueno le encuentras la maldad. Bacán, está bien, encontrarle el subtexto... pero tiene que ver también con no tolerar las cosas como son (Roberto).

Si estas defensas más cotidianas no funcionan, se extrema la defensa, lo cual incluye la negación, que puede ser más o menos consciente, rechazándose de plano el contenido en cuestión, o eventualmente renunciando a hacer el trabajo:

Susana, por ejemplo... le llegó que le dieran siempre los mismos personajes, porque ella era así, pero estaba en bronca con ser así, (...) no toleraba verse como la buena esposa, que le sacan la vuelta y ella comprende. No toleró, y ya no hace teatro, se dedicó a sus negocios (Carlos).

Y ahora recién entiendo esa reacción de Jaime de rechazar ese personaje. Y de sentirse tan mal (...). Y que ni el director ni las actrices compañeras lo entendieron. Y que creyeron que era una pose. (...) Es que él realmente vio la dimensión real de esta cuestión, pues. Y tuvo una reacción de huida, quizá un poco histriónica (ríe), tirar la taza de café y esas cosas (ríe), pero creo que fue esencialmente real (Roberto).

1 Ionescu, Jacquet y Lhote (2001) han encontrado tres listas clásicas de mecanismos de defensa (según Valenstein, Vaillant y el DSM-IV) que consideran el humor dentro de ellos. 
En otros casos la defensa y el cuidado es mucho más consciente y se rechazan trabajos porque se anticipa que no habrá una contención, y al igual que en un proceso terapéutico, donde debe establecerse primero una confianza y una alianza de trabajo que permita la asociación libre con cierta garantía, el actor también busca un contexto de trabajo que lo proteja:

Dentro de mí hay una puerta y un dique enorme que nadie conoce. A eso me refiero con esa dificultad de que me contengan. Y además sobre todo porque ha estado tanto tiempo atrapada que, al principio, de salir, sale con mucha mierda, una vez que se va la mierda comienza a quedar lo bueno. Pero no hay quién quiera ver esa mierda. A eso me refiero cuando digo que no confío en que haya un director que me contenga... (Eduardo).

En cuanto a las explicaciones para los fenómenos defensivos antes descritos, los entrevistados también aportaron. Entre las causas que identificaron están, en principio, el riesgo inherente al hecho de que el actor tiene como herramienta fundamental sus propias emociones, lo cual lo coloca en una situación de fragilidad, como señala $\mathrm{Ca}$ mila: “... porque además tú sabes que si sacas tus emociones a flor de piel y tal, eres mucho más débil, más herible, eres un blanco fácil de todo".

Si se dan las confusiones entre un actor y el personaje que está representando, podemos asumir que la emoción que ha surgido se acerca más a una emoción primaria, y esto a su vez es causado quizá por lo masivo de los procesos de proyección e introyección, o por las características psicológicas estructurales del actor, junto, en algunos casos, a una falta de preparación en la técnica actoral. Los entrevistados opinan, efectivamente, que la pérdida de control y las confusiones con el personaje son fenómenos no inherentes a la actuación en sí:

En el juego teatral se trata de no sentir realmente, y en la técnica, la preparación supone que tú realmente no llegas a sentir. (...) El trabajo de un actor en escena no puede ser sentir. Porque si yo siento en escena, no voy a poder contar la historia. No existe forma. Las dos veces que yo me he dedicado a sentir, a sentir, me tuve que ir, tuve que parar (Manuel).

Así mismo los entrevistados parecen tener un reconocimiento de que las identificaciones pueden darse en dos niveles: uno funcionalizable, que tiene que ver con estados conscientes y con el manejo de la técnica, y otro el de identificaciones más confusas o inconscientes, en donde el actor tiene algún tipo de patología o perturbación, sea esta pasajera, situacional, o más permanente, o, por otro lado, una falta de manejo de la técnica actoral.

Nos parece importante destacar que puede, sin embargo, tratarse de identificaciones inconscientes y hasta duraderas, sin que esto implique alguna perturbación en el actor. Hethmon (1986) plantea que se trata, en la actuación, de emplear las experiencias alma- 
cenadas en el inconsciente, muchas de ellas no factibles de ser traídas a la conciencia con facilidad, o en todo caso aquellas que cuando emergen a nuestro pensamiento consciente, lo hacen de modo disfrazado, como en los procesos oníricos.

Nosotros pensamos que en el proceso de creación de un personaje, muchas veces se trata efectivamente de dejar fluir cosas lo más relajadamente posible, a modo de asociación libre, apareciendo cosas que a veces parecen no tener sentido, contenidos que a veces se descartarán o se conservarán dependiendo de si sirven o no para armar el personaje, pero cuya lógica de conexión puede ser en principio inconsciente. Este proceso implica, evidentemente, un cierto nivel de regresión, y su objetivo, por supuesto, no es la elaboración personal. Sandler (1986), por su parte, nos recuerda que existe una identificación primaria diferente a la descrita por Freud, y que implica la evocación refleja de la conducta y sentimientos observados en otro, que ha pasado a formar parte de un repertorio interior del sujeto (del reservorio de experiencias, diría Stanislavski), y que no es consciente. Los entrevistados opinan respecto a este último tema:

Son dos niveles. El nivel de lo funcionalizable, de lo que se necesita y se usa para el entorno teatral, donde sí hay identificaciones entre el actor y el personaje, identificaciones que el actor más o menos vive... en una situación de riesgo, en una situación de precariedad, haciendo emerger, o abriendo un poco las grietas de su psiquis con la posibilidad de que algo más surja, sin perder de vista que es para crear desde dentro de sí un personaje, pero lo hace conscientemente. Pero en otro nivel, cuando se da, y se pierde la perspectiva, estamos hablando de casos muy concretos, creo que eso no es intrínseco en el fenómeno de la actuación. Es una patología particular (Eduardo).

En relación con lo anterior, recordemos que Laplanche y Pontalis (1983) opinan que las identificaciones siempre van a alterar o transformar, por lo menos parcialmente, la personalidad previa a la nueva identificación. Esta es, por otro lado, la finalidad de la identificación (Freud, 1983h).

Si pensamos, además, en la finalidad de las identificaciones en el trabajo de interpretación teatral, esta sería la empatía. La empatía surge de la posibilidad de identificarse con el otro, de coincidir con él en lo esencial, y ello parece ser un requisito para poder conocer, incluso en aspectos no verbalizables, al personaje. No podría interpretarse con brillantez, creemos, un personaje al cual no se conoce profundamente, más allá de lo consciente. Winnicott (Panceira, 1997) hablaba de identificación primaria entre el infante y su madre, identificación que solo podría darse fuera de este contexto en regresiones muy profundas. Creemos que el trabajo de creación de un personaje es un proceso regresivo, aunque por supuesto controlado, y asumimos que un personaje, al no ser real y no poder ha- 
blar, solo puede ser comprendido a través de un fenómeno similar.

Retomando la idea de que el teatro no es terapia, este reconocimiento implica que se prioriza en dicha disciplina el resultado artístico, dejando de lado la elaboración de tales movilizaciones. Habría que comprender la necesidad de resolución de los contenidos que emergen, y buscarla fuera del ámbito teatral.

Por otro lado, opinamos que, en un acto de creación verdadera, necesariamente se debe uno desprender del producto creado. Luego de ello, uno mismo se re-crea reintroyectando ese producto que de alguna manera pasa a formar parte del mundo interior, por ejemplo, incorporando el vínculo que uno establece con su propio producto. Esto produce un enriquecimiento interior. En los actos creativos, sean artísticos o más prototípicos como el acto mismo de crear una vida, el resultado es gozoso. (No en vano, recordemos, al festejar un estreno los actores suelen comentar: "ya parimos" o "qué parto tan difícil"). Pero podría suceder también que el segundo paso no se concrete, y que el creador permanezca percibiéndose como vaciado. Según Weissman (1961), este es el caso de los actores, quienes en su mayoría, luego de cada representación, regresan a un self vacío, y el motivo por el cual los actores esperan con tanta ansiedad una nueva función, y se desesperan si esta no llega. Deseamos plantear que en nuestras observaciones, muchas veces los actores, habiendo disfrutado de su trabajo, se alegran de haber terminado una representación, pues entonces pueden regresar a una realidad que no parece tener carencias profundas, ni estar desinvestida de afecto.

Por otro lado, los entrevistados identifican dos etapas en el proceso: los ensayos (en donde se pueden sentir confundidos, es una etapa de búsqueda, de acercamiento, y por lo tanto de riesgo), y las representaciones (en donde hay, en principio, mayor organización emocional, pues el personaje ya está armado).

Pero ya no es el proceso en el cual estás arriesgando todo el tiempo, porque ya para la representación tú tienes que haber acabado el proceso creativo. (...) Tú tienes que terminar el trabajo para presentarlo, lo vas a mejorar, pero no lo vas a mejorar en escena (Manuel).

Entonces en el proceso creativo, tú te pones en riesgo, tú puedes poner toda tu capacidad emocional y sensorial al servicio de tu trabajo, y puedes desbordarte en ese riesgo. (...) Pero eso no lo puedes hacer cuando estás con público, porque si te caes te matas, cagas el espectáculo, por último, si no te importas tú... (Carlos).

En el material obtenido aparece también la distinción entre dos niveles de conciencia, ya que el actor se disocia instrumentalmente y una parte suya entra en la convención de la verdad teatral, mientras que otra parte suya sigue en la realidad concreta, de la misma manera en que un analista o terapeuta 
se disocia instrumentalmente, y le pide también a su paciente que lo haga:

A veces decimos estás viviendo el personaje... pero hay un nivel de conciencia de que si se abrió la puerta más tarde porque te tienes que ir, o si se ha caído esto, o si el vestido de la compañera está rasgado cómo hacemos para avisarle, y no dejas tu personaje... (Roberto).

Kernberg (1994) había ya resaltado este fenómeno de la doble observación: el hacer, en tanto a la vez uno se observa hacer. Esta autoevaluación es muy valorada por dicho autor, pues es justamente esta autopercatación la que estaría faltando en la psicosis, a diferencia de la creación, como plantea Manuel: “... se ha caído algo y lo recoge, se sale de su marcación para recogerlo, qué sé yo... es lo que le permite no volverse loco, digamos".

Sin embargo, aun cuando esta disociación instrumental esté presente, el trabajo del actor plantea una paradoja, que el comentario de Eduardo grafica:

Pero la realidad ficcional es en ese momento mi realidad. Es la realidad a la que yo me meto. Y mi precariedad está en que eh... comprometo mi estabilidad, por lo menos temporal, en esa actividad en ese momento (Eduardo).

Esta viñeta nos da la oportunidad de señalar un paralelo en cuanto a la institución de los límites de la realidad en la evolución del infante, y el proceso creativo. Winnicott (Panceira, 1997) decía que el niño se identifica al principio de su vida con la madre de tal forma que no percibe la diferencia entre ellos, pues la madre, identificada con la realidad de su bebé, coloca su pecho en el momento y lugar precisos en que el infante lo está creando en su fantasía, dándose la ilusión de omnipotencia. Pero este vínculo ideal no puede mantenerse, y la realidad se le irá imponiendo gradualmente, en un espacio intermedio y transicional, donde aparecen objetos y fenómenos transicionales que poco a poco también irá dejando, que más bien seguirá transformando en un modo de funcionamiento mental que tiene que ver con algo intermedio entre el mundo interno y el externo, con la fantasía y la realidad.

La transicionalidad puede ser vista entonces como la precursora de la creatividad y de los fenómenos culturales. El paralelo al que aludíamos está dado desde el hecho de que el trabajo del actor, como hemos visto, es necesariamente regresivo ("comprometo mi estabilidad"). Hemos planteado también que el actor se identifica inconsciente y automáticamente con su personaje, proyectándole aquellos contenidos que necesita proyectar, sin observar esta identificación, para luego, gradualmente, ir reconociendo la realidad exterior, que no es otra que el reconocimiento de que el personaje es una realidad diferente a la suya. Podemos decir que el actor, en virtud de su necesidad, ha experimentado la ilusión de haber creado algo (el personaje) que ya estaba allí, y que poco a poco irá reconociendo como independiente de él. El actor, al ir 
creando un personaje, se siente muchas veces omnipotente, $\mathrm{y}$ muchas veces también se lleva fuera del escenario indumentos o utilería que le recuerdan que el personaje no está presente fuera del escenario, pero que lo estará cuando regrese a él. Y en esta experiencia, su fantasía se irá convirtiendo en un acto verdaderamente creativo.

Para terminar con este primer eje temático, queremos resaltar que el actor se identifica con las propias emociones desde su propio cuerpo y los procesos fisiológicos de este. No imita, sino que se identifica con aquello que ya está dentro suyo. Todo lo que el actor experimenta mientras está actuando son experiencias que, una vez más, pasarán a formar parte de su mundo interior, del cual han sido creadas y hacia el cual retornan, modificándolo en algún nivel. En otras palabras, la identificación consigo mismo es un proceso ininterrumpido en el trabajo del actor.

\section{EL ACTOR Y SU HISTORIA}

Parece evidente que para entender por qué una persona realiza un trabajo de determinada manera, hay que conocer las motivaciones hacia tal vocación. En las historias personales y fantasías infantiles de los entrevistados encontramos que esto no es diferente respecto a la actuación. Los entrevistados afirman que entre sus motivaciones para actuar, tal vez la más importante sea la necesidad de vivir otras vidas y situaciones, que uno no está capacitado para vivir en la realidad; o buscando un permiso socialmente aceptado y aplaudido de hacer en el escenario cosas que no se harían en la realidad:
... queremos tener licencia para ser otras personas, una licencia para soñar, pero esas otras personas, los personajes, a la vez son tú... Y la gente se la cree, yo también me lo creo, durante un rato. Es un permiso para soñar... (Carlos).
En general siempre todo me ha dado miedo. Es como si en el teatro pudiera arriesgar lo que en mi vida no puedo arriesgar... Como que vuelcas en tu tra- bajo lo que en tu vida diaria no puedes hacer (Manuel).

En estas viñetas observamos la posibilidad de sublimación y de identificarse con aspectos no manifiestos de la propia personalidad. Llevando al extremo los comentarios ofrecidos por los entrevistados, podríamos pensar en personalidades vacías que asumen un papel porque este les otorga temporalmente una identidad, personalidades que solo existen en la medida en que se mimetizan con otro (en este caso el personaje). Sin embargo, quisiéramos destacar aquí que los entrevistados también reconocen que aquello que está en juego son aspectos propios. Entonces, aun si partimos de observar una carencia (algo que al actor le faltaría vivir) que conduce a la persona a la actividad interpretativa, en esta actividad se logra una sublimación. La actuación puede ser vista, pues, como un intento de autocuración.

Otra de las motivaciones encontradas en los entrevistados es la búsqueda 
de autoconocimiento. Como hemos planteado antes, los actores encuentran en la actuación una forma de acercarse a sí mismos, una forma de enriquecimiento personal, también relacionada con la sublimación. Si bien en muchos casos este autoconocimiento no es buscado activamente, sino que es más bien algo que uno puede aquilatar en retrospectiva (como en el ejemplo de Carlos que presentamos a continuación), o que, en última instancia, no llega a sistematizarse nunca, en muchos otros casos el trabajo puede ser sumamente introspectivo:

... me sirvió en todo caso para reflexionar en cómo era yo en esa época, y las tonterías y locuras, en buena onda, que hacía, pero esas tonterías y locuras las hacía Sebastián, este personaje, y gustó mucho porque era loco, era un loco simpático, y así era Carlos, así era yo, pero sí fue una retrospectiva, fue como tener... una conversación conmigo mismo... (Carlos).

Porque en todo esto no ha habido más que la búsqueda de mí mismo, el encontrarme conmigo mismo... Y por qué no seguir, si con esto... me estoy encontrando realmente, a mí mismo, si con esto puedo hablar con claridad, como he hablado ahora, de mí, de mi vida misma... si después de años puedes hablar y tener las cosas... que quizá en otra profesión no las hubiera tenido claras, y porque (...) en todo esto de la ficción y de contar historias, primero es contártelas a ti mismo ¿no? (Roberto).

La necesidad de dominio o control aparece también entre las motivaciones para la actuación. Se trata de dominar al público en tanto se logra su atención absoluta, así como dominar algunos contenidos propios del actor en un intento, quizás, de elaboración. El dominio tiene que ver también con dominar la propia situación vital a través de garantizarse el actor, en el fenómeno escénico, la mirada del otro (público, director, otros actores-personajes). Relacionamos con todo ello algo que Lowenfeld (1941) ya mencionó, al decir que todo artista creativo debe haber tenido experiencias traumáticas tempranas que producen una necesidad de repetir activamente lo que se experimentó originalmente de forma pasiva. Adelantamos aquí algo que desarrollaremos con mayor detenimiento posteriormente, que es el hecho de que aquello que se reproduce, en última instancia, es el vínculo primario con la madre:

... adquirir de alguna manera confianza en cosas, y cómo confías... tienes un guión, pues (...) mi único apoyo durante muchos años ha sido mi guión, mi libreto, incluso cuando iba a análisis tenía que escribir algunas cosas. Y lo bacán ha sido el proceso de dejar el guión, e improvisar hasta en la vida ¿no? A ver qué sale... (Roberto).

... el teatro te da la posibilidad de dominar a la gente, porque tú la dominas, tú sabes cuándo la gente te está escuchando con atención y cuándo no, (...) como también es interesante saber que la gente está recibiendo lo que tú estás diciendo como tú lo querías... (Carlos).

Otra de las motivaciones mencionadas por los entrevistados es la necesidad de vibrar, la búsqueda de intensidad, fenómeno que los entrevistados 
relacionan con una necesidad de llenar vacíos, lo cual pasa incluso por una búsqueda de límites corporales, en donde a veces el actor se identifica consigo mismo y con su propia madre, en una relación primaria. Weissman (1961) decía que cuando termina una representación, se regresa a un self vacío e incompleto. Hay un deseo en el actor de revivir la relación temprana con la madre, en donde la audiencia es una parte del self que está faltando. Unamos esta idea con la anteriormente expuesta de Lowenfeld (1941) respecto de que los artistas deben haber pasado por experiencias traumáticas tempranas y tenemos que parece probable que, efectivamente, agregamos, esa experiencia traumática temprana tenga que ver con una dificultad en la mirada materna. Se trata de llenar un vacío primordial, una falta de mirada de la madre, en donde se busca generar una situación que garantiza una experiencia emocional correctiva de la experiencia inicial de incompletud, en un contexto confiable, pues la contención está de alguna manera garantizada:

... la necesidad de vibrar... vibro, luego existo. O sea, no existo si no actúo. Y si no vibro no tengo sensación de mi piel, no tengo sensación de mi cuerpo, de mi interioridad. Al vibrar siento mi sangre correr, mi corazón latir, mis pulmones respirar, siento mi piel... erizarse. $\mathrm{Me}$ siento, me reconozco, me hallo, este... presente, vivo, aquí, ahora. Si no vibro, si no siento, soy etéreo, no tengo cuerpo, no tengo forma, no tengo límite. Para algunos actores la motivación para actuar es reproducir una sensación de precariedad de identidad, que tienen desde hace mucho, y brindarse a través de la actuación la oportunidad de modificarla. (...) En mi caso lo sentía en la piel... una sensación de volumen muy fuerte, de estar como envuelto. Con todos los símiles que esto puede acarrear...el útero y todo lo demás ¿no? (Eduardo).

... pero a la vez el actor está todo el tiempo mirándose. Todo el tiempo consciente de que no es él. Esa es la paradoja. (...) Porque es él mismo el que se mira, es él mismo el que se mira y dice estás bien o no estás bien, estás sintiendo o no estás sintiendo. Te reconozco o no te reconozco... (Eduardo).

... una sensación de incompletud. Uno solo puede completarse a través de la mirada del otro. (...) porque también hay una interdependencia que está absolutamente garantizada... El acto vital de vivir una circunstancia en la que el otro te va a responder como esperas que te responda. Yo pienso que puede tratarse de una especie de ausencia que te lleva a buscar completarla, a buscar taparla con la relación con el otro, con la imagen que el otro te devuelve, el público o el otro actor. Inclusive el director (Eduardo).

Pensamos que sería importante destacar aquí el lado exhibicionista del actor, planteado en la literatura (Ekstein y Friedman, 1957; Weissman, 1961), en donde el término exhibición carece de su connotación popular en cuanto frivolidad, vanidad y hasta superficialidad. En realidad, parecería que en los actores, el exhibicionismo es un fenómeno más íntimo, y más profundo, que tiene que ver con la necesidad de mostrarse ante la mirada del otro de una 
manera muy íntima, con un mostrar íntimamente a cada una de las personas de la audiencia, o a la audiencia global, convertida en la madre que puede responder a esa exhibición. El compromiso principal no está dado en la fase fálica (que obviamente, sin embargo, también está involucrada en cualquier tipo de manifestación histriónica), sino en la de la temprana fase oral.

Por otro lado, las experiencias emocionales intensas, decía Kernberg (1994) alientan, si son dolorosas, la separación, y si son placenteras, la fusión. Recordemos que los entrevistados han planteado en todo momento la intensidad emocional del trabajo de actuación. Si unimos esta premisa a la idea de que el trauma es una precondición para el trabajo creativo en la medida en que se pugna para el paso de la pasividad a la actividad (Lowenfeld, 1941), podemos sugerir que el actor busca activamente repetir vivencias emocionales intensas con el fin de elaborarlas.

Encontramos en el material recopilado también la búsqueda de reconocimiento y aceptación social, como una extensión de la mirada de la madre. El actor efectivamente busca en la audiencia el objeto primario y vive una relación amorosa con ella, por lo cual quizá es tan frecuente encontrar frases como "mi público me ama", "yo vivo para mi público".

Una quinta motivación encontrada en los entrevistados fue la búsqueda de sentido, que podría relacionarse con la ficción y el hecho de que el teatro plantee mitos universales, ya que al ponerse en contacto, a través del teatro, con dichos mitos y conflictos universales, el actor parecería estar intentando acercarse a las respuestas. En relación con esta motivación encontramos también una búsqueda de ubicación en un entorno personal confuso. No se trata, por supuesto, de una característica exclusiva de los actores, que, sin embargo, han encontrado en el teatro una manera de sublimar está búsqueda.

Un ejercicio que se hace muchas veces en teatro es el del cosmos... establecer rutas de movimiento entre la gente, que no se choquen, que no se estorben mutuamente, es la dinámica del teatro, de una puesta en escena, es un cosmos en el que todos tienen un sentido, una función, una participación, una identidad. Expulsados del paraíso buscamos eternamente nuestro lugar, nuestra identidad... una ausencia constitucional a la historia del ser humano... (Eduardo).

Finalmente, aunque no menos importante, aparece la búsqueda de catarsis como motivación para la actuación. Aunque los actores identifican la catarsis como un fenómeno inherente a la actuación, el motivo inicial por el cual surge el teatro en la historia de la humanidad, reconocen que esta no es la finalidad de la actuación. Plantean, sin embargo, que es inevitable, y que en algunas ocasiones es buscada conscientemente. Esta catarsis puede buscarse con dos finalidades: dejar fluir las emociones para exorcizarlas y elaborarlas, o con la finalidad de buscar simple- 
mente el caos, siendo esto, en opinión de los entrevistados, dañino para el actor:

... descubrir con qué facilidad te puede salir ese lado de maldad, eso es lo que más me llama la atención. Acabo de hacer un personaje que se pelea a muerte con otro, que lo hacía Carlitos, y me peleé y le saqué la mierda, (ríe), tan es así que nos reíamos comentando luego que tantos años pensando que lo que necesitaba era sexo y lo que necesitaba era bronca, hacía años que no me peleaba con nadie... qué fácil, te opones a la violencia, pero cuando está permitido, cuando sabes que no hay un compromiso real de violencia, sufres ese ratito, te enojas ese ratito, eres mala ese momentito, con placer, porque es lógico, sería antinatural que el personaje se reprima si es que no lo pide el texto... (Camila).

Recuerdo más haber usado este... personajes, para catarsearme, eso sí, para hacer catarsis, O sea... estoy en crisis ahorita, me he peleado con mi mujer, entonces mi personaje va a sufrir ese día, ya, yo sé que va a sufrir ese día, entonces voy a aprovechar el sufrimiento del personaje para sufrir yo. Voy a hacer catarsis. Yo creo que es inevitable que el trabajo del actor sea un trabajo catártico... en muchos casos es saludable, en muchos casos es insano. Ahora, si tú vas a hacer catarsis para crecer, te estás metiendo en riesgo en función a un criterio de crecimiento. Pero si vas a hacer crisis para hacerte daño, no es el lugar más adecuado, porque cagas las dos cosas. Tu vida y tu trabajo (Manuel).

Es importante señalar que, en todos los factores que los entrevistados refieren como motivaciones para la actuación (salvo en la búsqueda de catarsis), se puede observar en última instancia, la misma necesidad originaria. Desde todo punto de vista, pues, la motivación para actuar tiene que ver con una experiencia correctiva emocionalmente, que solo es vista así después de un tiempo de trabajar en el teatro, en virtud quizás de sus efectos.

\section{FUERA DEL ESCENARIO HACIA LA}

\section{REALIDAD}

En este eje analizamos cómo las identificaciones pueden llevarse fuera del contexto teatral, llegando incluso a afectar la vida personal del actor, y a tener un impacto sobre el entorno de este, por supuesto siempre en grados diversos. Por otro lado, analizamos también cómo el entorno puede, por su parte, reforzar estas identificaciones. La naturaleza del trabajo del actor propicia estos fenómenos en tanto, como hemos visto, el actor está todo el tiempo identificándose con diferentes aspectos de sí mismo:

En casi todas las otras profesiones, actividades, el trabajo o la actividad profesional es un distractivo, de tal manera que cuando tu trabajo es muy absorbente, descuidas tu vida cotidiana. En el trabajo del actor estás trabajando contigo, permanentemente. Y te llevas el trabajo a la casa, y te llevas la casa al trabajo... (Manuel).

Consideramos en este eje algunas dimensiones, la primera de las cuales tiene que ver con continuar representando un personaje fuera del escenario. Según Weissman (1961), existe en el actor una búsqueda de equilibrio al re- 
presentar un personaje, pues este le da la oportunidad de buscar una autoimagen que cumple una función homeostática. Al terminar la función hay un regreso a un self vacío. Tal vez esto explique el siguiente caso:

\begin{abstract}
Álvaro Gutiérrez siempre fue conocido por eso, porque se convertía en sus personajes. Si un personaje era depresivo, él también era depresivo. Él hizo un montaje donde hacía de viejo, y en esa época yo me lo crucé dos veces, en la calle, y caminaba del brazo de su mujer, como un viejito, y él estaba muy bien, no tenía ningún problema físico. (...) Y era evidente que no estaba ensayando... Después lo vi en un montaje, donde recreaba personajes de Chejov, y paraba así, en drama todo el tiempo, totalmente diferente a lo que él era...Y me han contado que siempre le pasaba eso, que si sus personajes eran así, él también era así durante un tiempo (Manuel).
\end{abstract}

Encontramos, por supuesto, casos menos dramáticos:

Hice un personaje que era una basurita, y yo sí tenía actitudes fachistas, y fuertes, en mi casa también, sí, allí sí me envolví, me atrapé, o me atrapó el personaje, de una manera relativamente fuerte, digamos. Pero, en general, durante una temporada sí, definitivamente, tengo actitudes del personaje que estoy representando (Carlos).

Por otro lado, el actor puede llevar estas identificaciones a la relación con otros actores, en alguna medida manteniendo una cierta indiferenciación con su personaje, o resultando indiferenciada su percepción del otro actor-personaje. Entonces, la confusión que hemos observado en la percepción del actor mismo, se extiende a la percepción de otros actores, identificados con sus personajes, en donde no resulta a veces claro a quién se está percibiendo o con quién uno se está relacionando. Se trata de una dimensión más abarcativa y social de los mismos fenómenos antes descritos. Observamos la puesta en marcha de varios procesos individuales que engranan entre sí, la combinación de varias subjetividades en donde los mecanismos de identificación proyectiva tal vez sean los más llamativos. Los ejemplos obtenidos van desde enamoramientos hasta rencillas y resentimientos. Hay un reconocimiento, por parte de los entrevistados, de que esto, sin embargo, no debería resultar del trabajo de actuación. Pero, sin embargo, estos fenómenos se presentan, y a veces por falta de experiencia:

Ahí sí yo creo que la técnica es fundamental. (...) Cuando ensayábamos XX, en un momento, dos de los chiquilines del coro me tenían que llevar presa, y yo les decía, papá lindo yo soy Camila y no me voy a escapar, mi personaje se escaparía pero la obra tampoco lo permite, de verdad no me ahorques, tenía todos los brazos morados, agárrame fuerte pero no me lastimes porque yo no me voy a escapar (Camila).

Algo que me ha pasado es que cuando yo me relacionaba con un personaje, voy practicando en la vida. Totalmente consciente, pero por momentos eso podía ser inconsciente, porque con este personaje yo llegaba al set y ya empezaba a actuar como él. Tanto que, relaciones amistosas que nacieron en ese trabajo, nacieron equivocadamente, porque 
yo no era así, y... la protagonista de esa novela me veía como el personaje (...), yo la sentí en un momento que ya no sabía cómo comportarse conmigo, porque antes tenía una idea, y después tuvo otra. Altera, altera pues las relaciones, definitivamente las altera... (Roberto).

\section{Estos fenómenos tienen incluso una} dimensión social aún más amplia:

Bueno, y por otro lado los personajes que se la creen, el estatus. Si hablamos de televisión, los personajes no solamente son los personajes, sino que son arquetipos reconocidos por la televisión y por la estructura de la televisión, y cada uno tiene una jerarquía, (...) tú eres más si eres el protagonista, eres... la cabeza de la jerarquía... entonces eso repercute en la persona (Roberto).

No solo se puede extender el personaje a la vida real, sino que también se puede extender una relación con otro personaje, esté signada esta relación por emociones positivas o negativas:

Desde que llegamos a la locación, Alberto me dijo con claridad sus intenciones sexuales sobre Karina (...). En principio lo tomábamos a la broma, pero luego empezó a intentarlo y al ser rechazado, poco a poco se fue convirtiendo en su personaje. (...) Luego me di cuenta de que en realidad era competencia conmigo. Porque en el ínterin, Karina y yo empezamos a acercarnos, me empezó a buscar a mí para contarme... como un apoyo. Entonces comenzó a reproducirse entre los actores el mismo triángulo, no con las mismas acciones, pero sí con el mismo tipo de relación que se estaba dando en el guión. Y eso se mantuvo hasta el final, y como su personaje perdía, en la vida real él se colocó también en la situación de perder... (Eduardo).
En realidad yo no estaba enamorado de Lucía, sino de su personaje, que era pareja de mi personaje. Yo la conocía ya mucho tiempo, y nunca había pasado nada. Una vez vi una secuencia de ella, la vi tan frágil, que me enamoré. (...) y no me di cuenta de que ella era totalmente distinta al personaje. Más bien yo quise ajustarla, pero, bueno pues... (Eduardo).

... mi personaje era un ángel, y ayudaba, mágicamente, hasta tenía poderes, una cosa medio hacia lo real maravilloso, y de alguna manera ahí sí me la creí, me sentía un tanto omnipotente, supongo, y con Viviana hubo mucho de eso, yo sentía que si alguien la podía sacar de la mierda en que estaba era yo, sentía una necesidad muy grande de protegerla, de salvarla. Y durante un tiempo fue así. Un tiempo largo. Eso ya no se pudo mantener después... (Manuel).

En XX yo tenía una relación con Pilar, un personaje, y yo extendí esa relación con la actriz... Completamente irreal. Era totalmente un juego (...). Pero hay algo que busca el personaje, que el actor conserva. (...) De diferente manera pero... confusión quizás es la palabra. El personaje estaba confundido. El actor estaba confundido, o quería confundirse. El personaje estaba confundido, y el actor buscaba la confusión. Ahí está la cosa, yo la confundí a ella (Roberto).

Me ha pasado cuando yo he hecho personajes malditos, pues, y tenía que insultar a la otra persona, y la otra persona puede haber sentido que era para ella, y no era para ella, era para el personaje que estaba haciendo. Y sí, sí, me han esquivado, me han evitado después... (Carlos).

Al prestarse para identificaciones, actores y personajes, en interdependencia, cada quien se está prestando para 
la exploración personal del otro. Y esto finalmente es lo que todos hacemos todo el tiempo en la vida misma, para que los otros se vayan constituyendo, y para constituirnos nosotros mismos. En tanto el teatro es un arte que recrea la vida misma, desde lo más subjetivo de las interrelaciones, este fenómeno se repite también. Sandler (1986) propuso, recordemos, que las identificaciones son perdurables.

El público también juega un rol en estos fenómenos al entrar en la convención de la ficción, algo que puede ser visto por el actor como anecdótico, pero que puede llegar a generar una presión social, en algunos casos:

Una vez nos fuimos a una fiesta comunal, estábamos varios actores, en una especie de salsódromo inmenso. Por supuesto éramos el centro de la atención, y yo empecé a bailar, como yo, empecé a tratar de divertirme y todo el mundo empezó a decir, ay, mira cómo baila... me... me reprimió un poco... y (ríe) incluso empecé a bailar creo como personaje, horrible... (ríe). Esto parece una anécdota sencilla, pero creo que lo puedo relacionar con no fallar, con mantener la apariencia y no fallarle a la otra persona, con tener que ser bueno ante otros ojos... (Roberto).

Y el público también funciona como un marco referencial que permite arriesgar contenidos:

El actor se fuerza a sí mismo, se coloca en una situación de riesgo, pero es una situación de riesgo aceptada socialmente, y socialmente protegida por la comprensión de que tanto el resto de actores como el público global te va a contener.
Si no confías en que el público va a proteger tu esfuerzo, tu riesgo, no lo harías, simplemente (Manuel).

El rol del director, por su lado, como se observa en la siguiente viñeta, es también esencial. Su rol debe ser el de contener, facilitar la emergencia de identificaciones que luego deberán ser contenidas. El director es visto, en gran medida, como responsable de que las identificaciones se mantengan dentro del contexto para el cual nacen, así como el responsable de no permitir que el actor se haga daño. Los entrevistados opinan al respecto:

El trabajo del director es de muchísimo cuidado, tiene que proteger al actor de que no se haga daño, porque al sacar sus emociones eres un blanco fácil de todo (Eduardo).

... si efectivamente tienes una buena técnica, un buen director... Esas cosas van a hacer que todo esté al servicio del personaje (Camila).

Es así que el director es más o menos un yo auxiliar en el proceso, responsable de conducirlo. Nuetzel (1995) ha planteado que el director no solo tiene que lidiar con transferencias individuales, sino además con transferencias grupales.

Ahora bien, una dificultad planteada desde el inicio de esta investigación fue determinar si, al entrar al tema de las identificaciones, podemos hablar de dicho fenómeno, en el sentido psicoanalítico, si estas son conscientes. $\mathrm{Y}$ en la mayoría de ejemplos ofrecidos por 
los entrevistados parecería que lo son. Sin embargo, en muchos ejemplos, sobre todo en aquellos respecto de otros actores, puede apreciarse que los fenómenos observados por los entrevistados son inconscientes para quien los exhibe. No olvidemos que aquello inconsciente puede, en gran medida, ser traído a la conciencia. Por otro lado, parecería también que en muchos de los casos las identificaciones y las confusiones entre actor y personaje no son conscientes mientras están sucediendo, sino que se hacen conscientes a posteriori, con la elaboración que los actores tienden a buscar casi constantemente. Esto va de la mano con lo que creemos es la motivación principal para la actuación: la búsqueda de sí mismos y la construcción de un self más auténtico a partir de la disolución y la recreación de imágenes.

Las actuaciones (en el sentido de $a c$ ting-out) en contextos analíticos suceden inconscientemente, y lo mismo parece ser cierto para las actuaciones en el proceso de creación teatral, y en ambos contextos también estas actuaciones se reconocen solo en retrospectiva. Nuetzel (1995) ha afirmado que en el teatro, las actuaciones (acting-out) son expresiones inconscientes de emociones que están en el texto de la obra y que se suscitan con el propósito de desarrollar un trabajo interpretativo. Cuando esto se hace consciente, lo que ha sido descubierto a través del acting-out es incorporado a la actuación teatral.
Nos parece importante recordar aquí, además, que la identidad puede verse como un concepto global, pero que también puede hablarse de identidades parciales, que son las que parecerían estar en juego en el fenómeno de creación de un personaje.

Queremos vincular, por último, el nivel de conciencia de las identificaciones también con el trabajo de Stanislavski (1989), quien explicitó haber buscado por mucho tiempo un "camino consciente hacia el inconsciente". Stanislavski estaba convencido de que trabajar con el inconsciente todo el tiempo era un error fundamental, y una de las peores distorsiones de la actuación. Planteaba, entonces, un trabajo que utilizara material inconsciente, suscitado a través de técnicas asociativas específicas al teatro, para que una vez manifestado se elaborara y se hiciera consciente, por supuesto para fines del producto teatral.

\section{Conclusiones}

En cuanto a la identificación entre actores y sus personajes hemos comprobado que se trata de un fenómeno que aparece constantemente en los procesos de creación de personajes y hemos sugerido que se trata de fenómenos inconscientes, aunque susceptibles de ser elaborados a nivel consciente, por lo general a posteriori. Una parte de tales identificaciones, sin embargo, con seguridad, inevitablemente permanece inconsciente. Estas identificaciones 
pueden o no resultar perdurables y modificar la personalidad del actor, aunque hemos sugerido que generalmente se trata de identificaciones parciales que, sin embargo, van constituyendo de forma gradual la personalidad, siendo que cada experiencia artística transforma o consolida una parte del mundo interno, al igual que lo hace cada experiencia o vínculo en la vida real.

La manera en que se despliegan las identificaciones en el proceso de creación de un personaje parece seguir un patrón, que suele iniciarse con la proyección automática e inconsciente en el personaje de aspectos propios del actor. Hemos planteado que se trata de identificaciones proyectivas, en las cuales el actor continúa percibiendo tales aspectos propios en el personaje. Esto puede resultar problemático, generándose una necesidad de distanciamiento y diferenciación. Los contenidos proyectados en el personaje son luego reintroyectados, con una correspondiente fantasía de absorción corporal en la cual el objeto introyectado se siente activo dentro de uno. Todos los mecanismos de identificaciones proyectivas e introyectivas mencionados son, en principio, parciales, pero hacia la culminación del proceso de creación se encuentra, en el mejor de los casos, gratificación en una identificación introyectiva integradora, sentida como la realización de un buen trabajo de interpretación, pero que tiene que ver con una autoaceptación de ciertos aspectos.
Para que este proceso se establezca, el actor habitará lúdicamente al personaje y eventualmente permitirá que este lo habite a él, no sin antes haberse asegurado de establecer los límites entre ambos, con lo cual la regresión a la fusión resulta menos amenazante y le otorga una sensación de mayor control.

El proceso de irse encontrando el actor a través de las identificaciones con el personaje se hace problemático cuando la identificación es displacentera, es decir, si la característica que vincula a actor y personaje es un aspecto que el actor no puede aceptar en sí. Es así que el proceso resulta conflictivo y hasta doloroso si el actor no está en condiciones personales para interpretar un personaje en determinado momento de su vida, con el riesgo de que se produzcan fracturas psíquicas y la regresión a una etapa esquizoparanoide.

Consideramos que el fenómeno de las identificaciones entre el actor y sus personajes tiene una doble finalidad: por un lado, la creación de un personaje, y por otro, dado que los actores están comprometidos en una búsqueda $\mathrm{y}$ descubrimiento personal, una consolidación de aspectos propios del actor. Hemos destacado de manera principal que el actor busca identificarse consigo mismo y que la actuación es para los actores un medio de búsqueda y descubrimiento personal. Esto se ve reforzado por el hecho de que es imposible reproducir en el trabajo interpretativo algo que no esté ya inscrito, de modos 
más o menos escondidos, en el mundo interior del actor. Desde el punto de vista de la técnica actoral, esto sería además indeseable.

Hemos resaltado el hecho de que el proceso de la interpretación involucra profundamente al cuerpo, en donde llega a haber un cambio fisiológico, que propicia una identificación a niveles primarios y pulsionales, y desde el cuerpo, el actor se identifica con las propias emociones. No imita, sino que se identifica con aquello que ya está dentro de sí. Lo que el actor experimenta a través de su trabajo pasará a formar parte de su mundo interior, modificándolo en algún nivel.

En cuanto a los mecanismos defensivos establecidos por el actor para discurrir a través de estos fenómenos identificatorios, hemos encontrado que estos pueden ser más o menos rígidos dependiendo de la cercanía que sienta el actor con el personaje, del hecho de que se rechace una determinada característica de este, y de las características defensivas inherentes a la personalidad del actor. Hemos encontrado, así mismo, que la defensa más común evidencia una toma de distancia, generalmente a través de la caracterización, de la indiferencia (aislamiento), o del uso del humor. Otras defensas comunes son la racionalización o la intelectualización, en donde todo lo que hace el personaje tiene que estar justificado, o las defensas que implican convertir los contenidos en lo contrario, o la omni- potencia, o agregarle al personaje características que equilibren o den un balance hacia el extremo opuesto. En este grupo de defensas aquello que el actor busca parece ser el control.

Hemos observado también que si las defensas antes mencionadas no resultan exitosas, el actor puede recurrir a defensas más extremas como la negación, que puede ser más o menos consciente, rechazándose de plano el contenido en cuestión, o eventualmente renunciando a hacer el trabajo, en una manifestación de autocuidado.

En cuanto a las dificultades que podrían surgir en el proceso de identificaciones y defensas dentro del contexto del trabajo actoral, hemos observado confusiones que se suscitan dado el grado de movilización psíquica puesto en marcha durante la etapa de ensayos. Los ensayos son vistos como una etapa de búsqueda, de acercamiento, y por lo tanto de riesgo pues el personaje aún no está acabado, y aún no se han establecido los límites entre el actor y el personaje. La movilización de contenidos interiores puede llegar incluso a niveles estructurales, $\mathrm{y}$ pueden permanecen alterando al actor.

Entre las variantes de dichas confusiones tenemos que el actor puede llegar a confundirse con su personaje, y continuar representando un personaje fuera del escenario. Puede también el actor llevar la confusión a la relación con otros actores, y a la percepción de estos, no distinguiendo entre ellos y los 
personajes que representan. Las relaciones que se establecen con otros actores están a veces signadas por las emociones que los personajes despliegan, estableciéndose a veces relaciones engañosas en la vida real.

Estos fenómenos no son inherentes a la actuación, sino a la falta de experiencia o de manejo de la técnica, así como a la búsqueda de un equilibrio interno, con el que el actor intenta llenar vacíos, y eventualmente puede deberse a una perturbación, pasajera o estructural, en la personalidad del actor.

En cuanto a la salud mental del actor, consideramos que si las confusiones antes mencionadas se dan a niveles profundos, efectivamente podemos hablar de patología, pero hablar de una patología específica sería reduccionista. Hemos vinculado el fenómeno, sin embargo, en términos generales, con trastornos del self y con patologías de déficit, en las cuales la ausencia de una identidad consolidada hace que el actor busque que el personaje representado le otorgue una identidad. Consideramos, por otro lado, que el tema de la separación es crucial para abordar este aspecto, ya que si bien pueden existir fallas en la relación originaria con la madre, los actores parecen, en general, haber logrado una diferenciación suficiente para permitirse perder al objeto, ya que la ansiedad de separación es un tema recurrente en ellos, por lo cual las patologías depresivas pueden ser también comunes.
Existen elementos para pensar más bien que los actores suelen ser personas con una sensibilización especial para dar cuenta de sus procesos y motivos interiores, ocultos, procesos normalmente inconscientes para muchos, con una capacidad de introspección que han debido desarrollar para hacer bien su trabajo, con lo cual nos ubicamos ante personas con un yo flexible. Pensamos, así mismo, que el actor ha descubierto que el teatro es un canal socialmente aceptado para tal exteriorización de contenidos interiores.

Es imposible, sin embargo, generalizar, ya que asumimos la diversidad de individualidades. Hemos encontrado una amplia gama entre los logros sublimatorios y las patologías profundas. Respecto a este tema hemos planteado, además, que a mayor grado de equilibrio personal, menor riesgo para la persona que aborda el trabajo de creación de personajes.

Se ha observado también el fenómeno de disociación instrumental en el trabajo del actor, dado que una parte suya entra en la convención de la verdad teatral, mientras que otra parte suya sigue en la realidad concreta. Esta autoevaluación es vista como un indicador de salud, pues permite mantener la perspectiva de la finalidad del proceso, así como evidencia una adecuada prueba de realidad.

De las historias personales de los actores se desprende la observación de una búsqueda de equilibrio en su acer- 
camiento al teatro. En cuanto a las motivaciones para actuar, en general encontramos los siguientes aspectos: la necesidad de vivir otras vidas y situaciones que el actor cree que no puede vivir en la realidad, respecto de lo cual hemos destacado las posibilidades de sublimación y de identificarse con aspectos no manifiestos de la propia personalidad; la búsqueda de autoconocimiento, lograda generalmente en retrospectiva; la necesidad de dominio o control, lo cual implica dominar al público en tanto se logra su atención, garantizándose el actor, en el fenómeno escénico, la mirada del otro (público, director, otros actores-personajes); la necesidad de vibrar, la búsqueda de intensidad, relacionada por los entrevistados con una necesidad de llenar vacíos, en donde a veces el actor se identifica consigo mismo y con su propia madre, en una relación primaria, buscando una experiencia emocional correctiva de la experiencia inicial de incompletud; la búsqueda de sentido y de ubicación en un entorno predecible -en la medida en que se rige por un guióncomo puede ser el teatro; finalmente, la búsqueda de catarsis, a veces hecha de modo consciente, con la finalidad de dejar fluir las emociones para aliviarse, o, eventualmente, para hallar el caos.

Hemos encontrado, entonces, que la actuación le permite al actor un equilibrio emocional en la medida en que le otorga una identidad y un reconocimiento que no parece tener que ver tanto con el público como fenómeno actual, sino que se conecta con fallas en un momento de reconocimiento primigenio y fundante de límites psíquicos. El actor busca activamente, creemos, repetir vivencias emocionales intensas con el fin de elaborarlas.

El rol del director resulta crucial en todo el proceso, pues se ponen en él expectativas de contención que trascienden la finalidad artística. Postulamos que ese aspecto terapéutico debería ser buscado en contextos más pertinentes para ello.

Para terminar, queremos resaltar que pensamos que el valor de este trabajo es que de él se desprende la importancia fundamental de implementar, en las instituciones de formación actoral y de directores, instancias que tengan que ver con el acompañamiento personal y el cuidado del actor, que le ofrezcan al actor las herramientas para potenciar ese yo flexible que hemos observado en los entrevistados, destacándose la labor de prevención. 


\section{REFERENCIAS}

Abadi, S. (1996). Transiciones. El modelo terapéutico de D. W. Winnicott. Buenos Aires: Lumen.

Abadi, S. (1997). Desarrollos postfreudianos: Escuelas y autores. Buenos Aires: Editorial Belgrano.

Achard, L. (1962). Formas particulares de identificación en el actor. Revista de Psicoanálisis APA, 19 (1-2), 42- 48.

Alford, C. (1992). The psychoanalytic theory of greek tragedy. London: Yale University Press.

Del Valle, E. (1986). La obra de Melanie Klein. Buenos Aires: Lugar Editorial.

Ekstein, R. \& Friedman, S. (1957). The function of acting out, play action, and play acting in the psychotherapeutic process. Journal of American Psychoanalysis Assesment. V.

Ferenczi, S. (1982a). Introyección y transferencia. En: Obras completas, 93-125. Buenos Aires: Paidós. (Trabajo publicado originalmente en 1909).

Ferenczi, S. (1982b). El concepto de introyección. En: Obras completas, 196198. Buenos Aires: Paidós. (Trabajo publicado oroginalmente en 1912).

Fonagy, P. \& Target, M. (1996a). Playing with reality I: Theory of mind and the normal development of psychic reality. International Journal of Psychoanalysis, 77, 217-232.

Fonagy, P. \& Target, M. (1996b). Playing with reality II: The development of psychic reality from a theoretical perspective. International Journal of Psychoanalysis, 77, 459-476.
Freud, S. (1983a). La interpretación de los sueños. Obras completas. Madrid: Alianza Editorial. (Trabajo publicado originalmente en 1900).

Freud, S. (1983b). Tres ensayos para una teoría sexual. Obras completas. Madrid: Alianza Editorial. (Trabajo publicado originalmente en 1905).

Freud, S. (1983c). El narcisismo. Obras completas. Madrid: Alianza Editorial. (Trabajo publicado originalmente en 1914).

Freud, S. (1983d). Duelo y melancolía. Obras completas. Madrid: Alianza Editorial. (Trabajo publicado originalmente en 1917).

Freud, S. (1983e). Psicología de las masas y análisis del yo. Obras completas. Madrid: Alianza Editorial. (Trabajo publicado originalmente en 1921).

Freud, S. (1983f). El yo y el ello. Obras completas. Madrid: Alianza Editorial. (Trabajo publicado originalmente en 1923).

Freud, S. (1983g). El sepultamiento del complejo de Edipo. Obras completas. Madrid: Alianza Editorial. (Trabajo publicado originalmente en 1924).

Freud, S. (1983h). El malestar en la cultura. Obras completas. Madrid: Alianza Editorial. (Trabajo publicado originalmente en 1930).

García Bacca, J. (1989). La poética de Aristóteles. México: Editores Mexicanos Unidos.

Goffman, E. (1959). The presentation of self in everyday life. New York: Anchor Books.

Grinberg, L. (1978). Teoría de la identificación. Buenos Aires: Paidós. 
Halprin, D. (2003). The expressive body in life, art and therapy: Working with movement, metaphor and meaning. The arts in psychotherapy, 30, 243-244.

Hethmon, R. (1972). El método del Actor's Studio: Conversaciones con Lee Strasberg. Madrid: Fundamentos.

Hinshelwood, R. D. (1989). Diccionario del pensamiento kleiniano. Buenos Aires: Amorrortu.

Hughes, J. (1990). Reshaping the psychoanalytic domain. The work of Melanie Klein, W.R.D. Fairbairn y D.W. Winnicott. Los Angeles: University of California Press.

Ionescu, S., Jacquet, M., Lhote, C. (2001). Les mecanismes de defense: Théorie et clinique. Paris: Nathan.

Kaufmann, P. (1996). Elementos para una enciclopedia del Psicoanálisis. Buenos Aires: Paidós.

Kernberg, O. (1987). Desórdenes fronterizos y narcisismo patológico. Buenos Aires: Paidós.

Kernberg, O. (1994). La agresión en las perversiones y en los desórdenes de la personalidad. Buenos Aires: Paidós.

Klein, M. (1946). Notes on some schizoid mechanisms. En: Klein, M., Heimann, P., Isaacs, S. \& Riviere, J. (1962). Desarrollos en psicoanálisis. Buenos Aires: Paidós-Hormé.

Klein, M. (1955). On identification. En: Klein, M., Heimann, P., Isaacs, S. \& Riviere, J. (1962). Desarrollos en psicoanálisis. Buenos Aires: Paidós-Hormé.

Laplanche, J. \& Pontalis, J. B. (1983). Diccionario de psicoanálisis. Barcelona: Editorial Labor, S. A.
Lowenfeld, H. (1941). Psychic trauma and productive experience in the artist. Psychoanalitical Quarterly, X.

Moore, S. (1991). Stanislavski revealed. A guide to spontaneity on stage. New York: Library of Congress.

Nuetzel, E. (1995). Unconscious phenomena in the process of theater: Preliminary hypothesis. Psychoanalitical Quarterly, 64, 345-352.

Panceira, A. (1997). Clínica psicoanalítica a partir de la obra de Winnicott. Buenos Aires: Lumen.

Piaget, J. (1969). Epistemología genética. Buenos Aires: Paidós.

Roudinesco, E. \& Plon, M. (1998). Diccionario de psicoanálisis. Buenos Aires: Paidós.

Sandler, J. (1986). La identificación proyectiva. En: Sandler, J. (Comp.). Identificación, proyección, identificación proyectiva. Madrid: Tecni-publicaciones S.A.

Sandler, J. \& Sandler, A. M. (1999). Fantasía inconsciente, identificación y proyección en el poeta. En: Person, E., Fonagy, P. \& Figuerira, S. A. (Eds.). En torno a Freud: "El poeta y los sueños diurnos”. Madrid: Biblioteca Nueva.

Stanislavski, C. (1977). El trabajo del actor sobre su papel. Buenos Aires: Quetzal. (Trabajo publicado originalmente en 1949).

Stanislavski, C. (1979). El trabajo del actor sobre sí mismo en el proceso creador de la encarnación. Buenos Aires: Quetzal. (Trabajo publicado originalmente en 1951).

Stanislavski, C. (1980). El trabajo del actor sobre sí mismo en el proceso crea- 
dor de las vivencias. Buenos Aires: Quetzal. (Trabajo publicado originalmente en 1951).

Stanislavski, C. (1989). An actor prepares. New York: Routledge, Theater Arts Books. (Trabajo publicado originalmente en 1953).

Strasberg, L. (1989). Un sueño de pasión. Buenos Aires: Emecé.

Valls, J. L. (1995). Diccionario freudiano. Buenos Aires: Colección Continente/ Contenido.

Wallerstein, R. S. (1985). Defense, defense mechanisms, and the structure of the mind. En: Blum, H. P. (Ed). Defense and resistanse. New York: International University Press.

Weissman, P. (1961). Development and creativity in the actor and playwright. Psychoanalitical Quarterly, 30, 549566.

Winnicott, D. W. (1953). Transitional objects and transitional phenomena. International Journal of Psychoanalysis, 34, 2-89.

Winnicott, D. W. (1971). Juego y realidad. El espacio potencial. París: Gallimard.

Winnicott, D. W. (1979). El proceso de maduración en el niño. Barcelona: Laia.

Winnicott, D. W. (1992). Los procesos de maduración y el ambiente facilitador. Barcelona: Gedisa.

Winnicott, D. W. (1993). El niño y el mundo externo. Buenos Aires: Hormé. 